\title{
Heat Recovery from Multiple-Fracture Enhanced Geothermal Systems: The Effect of
} Thermoelastic Fracture Interactions

\author{
Vik, Hedda Slatlem ; Salimzadeh, Saeed; Nick, Hamid
}

Published in:

Renewable Energy

Link to article, DOI:

10.1016/j.renene.2018.01.039

Publication date:

2018

Document Version

Peer reviewed version

Link back to DTU Orbit

Citation (APA):

Vik, H. S., Salimzadeh, S., \& Nick, H. (2018). Heat Recovery from Multiple-Fracture Enhanced Geothermal Systems: The Effect of Thermoelastic Fracture Interactions. Renewable Energy, 121, 606-622.

https://doi.org/10.1016/j.renene.2018.01.039

\section{General rights}

Copyright and moral rights for the publications made accessible in the public portal are retained by the authors and/or other copyright owners and it is a condition of accessing publications that users recognise and abide by the legal requirements associated with these rights.

- Users may download and print one copy of any publication from the public portal for the purpose of private study or research.

- You may not further distribute the material or use it for any profit-making activity or commercial gain

- You may freely distribute the URL identifying the publication in the public portal 


\section{Accepted Manuscript}

Heat Recovery from Multiple-Fracture Enhanced Geothermal Systems: The Effect of Thermoelastic Fracture Interactions

Hedda Slatlem Vik, Saeed Salimzadeh, Hamidreza M. Nick

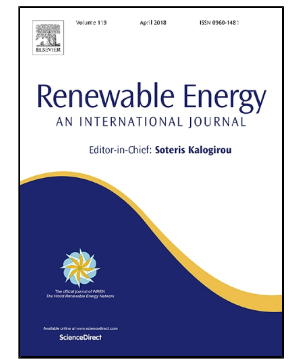

PII: $\quad$ S0960-1481(18)30039-9

DOI: $\quad 10.1016 / j . r e n e n e .2018 .01 .039$

Reference: $\quad$ RENE 9644

To appear in: $\quad$ Renewable Energy

Received Date: $\quad 04$ August 2017

Revised Date: $\quad 26$ December 2017

Accepted Date: $\quad 13$ January 2018

Please cite this article as: Hedda Slatlem Vik, Saeed Salimzadeh, Hamidreza M. Nick, Heat Recovery from Multiple-Fracture Enhanced Geothermal Systems: The Effect of Thermoelastic Fracture Interactions, Renewable Energy (2018), doi: 10.1016/j.renene.2018.01.039

This is a PDF file of an unedited manuscript that has been accepted for publication. As a service to our customers we are providing this early version of the manuscript. The manuscript will undergo copyediting, typesetting, and review of the resulting proof before it is published in its final form. Please note that during the production process errors may be discovered which could affect the content, and all legal disclaimers that apply to the journal pertain. 

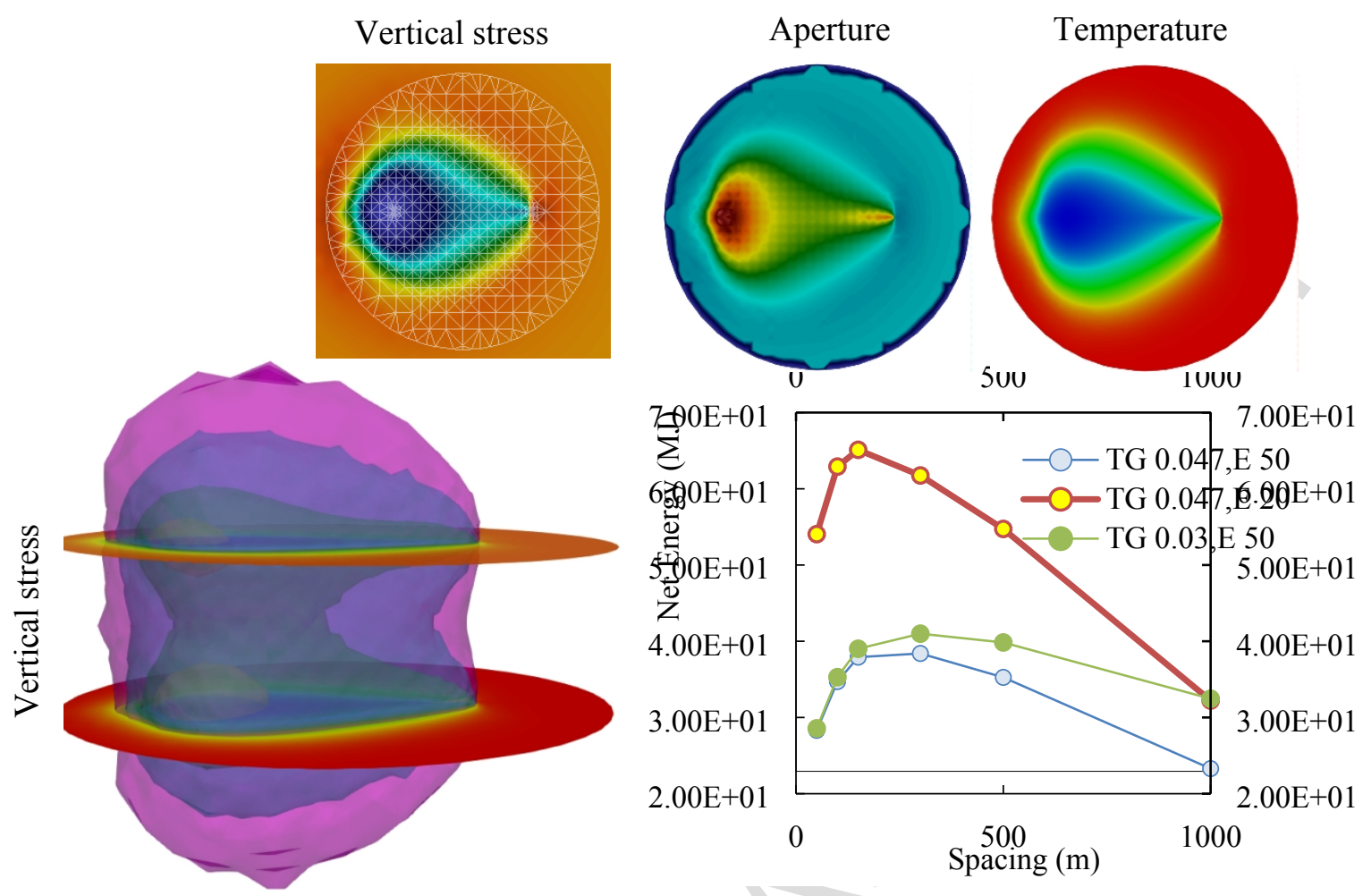


\title{
Heat Recovery from Multiple-Fracture Enhanced Geothermal Systems: The Effect of Thermoelastic Fracture Interactions
}

\author{
Hedda Slatlem Vik, Saeed Salimzadeh, Hamidreza M. Nick \\ The Danish Hydrocarbon Research and Technology Centre, Technical University of \\ Denmark, Lyngby, Denmark
}

\begin{abstract}
This study investigates the effect of thermoelastic interactions between multiple parallel fractures on energy production from a multiple-fracture enhanced geothermal system. A coupled thermo-hydro-mechanical finite element model has been developed that accounts for non-isothermal fluid flow within the fractures, conductive heat transfer in the rock matrix, and the mechanical deformation of the matrix. The model results show that the matrix deformation significantly increases the interactions between the two adjacent fractures. Matrix contraction due to the cooling of the matrix increases the fracture aperture in the adjacent fracture, and facilitates the creation of favourable flow pathways between the injection and production wells. These flow paths reduce the energy production from the system. The effects of fracture spacing, reservoir temperature gradient and mechanical properties of the rock matrix on the production temperature and the net production energy are investigated. It is shown that the spacing calculated based on the assumption of rigid matrix (constant uniform aperture) are too small, and in order to account for the thermoelastic interactions, the spacing between fractures should be further increased to maximise the net energy production from the system. Otherwise, the multiple-fracture system fails to improve the energy recovery from the geothermal reservoir, as initially intended.
\end{abstract}

Keywords: Multiple parallel fractures; Enhanced geothermal systems; Thermoelastic interaction; Fracture flow; Coupled formulation; 


\section{Introduction}

Geothermal energy is the energy stored in the Earth's crust and is one of the promising and clean renewable energy resources in the world (MIT, 2006). Geothermal energy can be used widely for district heating utilising the ground source heat pumps - GSHP (), and for power generation from conventional/enhanced geothermal systems. Based on the geological knowledge and technology, it has been estimated that in 2016 only 6 to $7 \%$ of the total global potential had been extracted (GEA, 2016). Low reservoir permeability is a common challenge for energy exploitation from deep geothermal reservoirs, and hydraulic fracturing is frequently utilised to improve the permeability within the reservoir. The stimulation has been widely used in the oil and gas industry and was introduced to geothermal projects in 1974 at Fenton Hill (MIT, 2006; Xie et al., 2015). In order to improve the heat extraction from the low permeability geothermal reservoirs, multiple induced fractures are proposed to provide multiple flow paths between the injection and production wells, and multiple contact surfaces for the heat exchange between the hot rock and the cold fluid (Bataille et al., 2006). Multiple fractures can improve the productivity of the geothermal system for a relatively lower cost (Schweitzer and Bilgesu, 2009).

In Enhanced Geothermal System (EGS), short-circuiting between the injector and producer wells is a common issue that affects the energy recovery from the system. Short-circuiting occurs due to the locally increased fracture aperture that creates a channel and prevent the cold fluid from accessing the bulk rock. The local increase in the fracture aperture is a result of the coupled thermo-hydro-mechanical and chemical (THMC) effects (Ghassemi and Zhou, 2011; Pandey et al., 2014; Guo et al., 2016). For the case of multiple parallel fractures, the mechanical interactions between the fractures further facilitate the creation of the unfavourable short-circuits between the injector and producer wells, reducing the fluid residence time and thus, reducing the energy recovery. Numerous analytical and numerical models have been proposed in the literature for studying the behaviour of enhanced geothermal systems. Due to very low permeability of the rock matrix in EGS, the fractures are considered as the primary pathways for the flow of the circulating fluid. For single fracture EGS, Bodvarsson (1969) derived an analytical solution for the problem of advectivediffusive heat transfer through a single one-dimensional fracture, while the heat is transferred through the matrix only by diffusion in the direction normal to the fracture (1D diffusion). Ghassemi et al. (2008) also proposed semi-analytical solution for a similar problem with leakoff of the fluid into the matrix. The apertures of the fractures vary during the lifetime of the EGS, as the cooling of the matrix results in matrix contraction and perhaps reduction of the contact stresses on the fracture surfaces (Salimzadeh et al., 2018a, b). The effect of thermoporoelastic deformation of the rock matrix on the fracture aperture and geometry evolution has been widely studied using numerical simulations for single fracture EGS (Ghassemi and Zhou, 2011; Guo et al., 2016; Abu Aisha et al., 2016; Pandey et al., 2017). The thermal contraction of the rock matrix together with the increased fluid pressure in the fracture decreases the contact stresses on the fracture surfaces and increases the fracture aperture. The reduction of the contact stresses promotes the shear deformation of the fracture (McClure and Horne, 2014), while the increase in the fracture aperture promotes the creation of unfavourable short-circuits. Guo et al. (2016) have shown that heterogeneity can aggravate the problem of short-circuiting.

The multiple-fracture EGS creates more flow paths, and gives access to a larger volume of rock. Gringarten et al. (1975) presented analytical solutions to parallel equidistant vertical fractures, highlighting the importance of the multi-fracture concept in the geothermal energy extraction. Recently, Wu et al. (2016) developed a mathematical model for the heat 
extraction from multiple horizontal fractures in a rigid medium (constant uniform apertures). Their results show that for the case of two parallel infinite rigid fractures, the thermal interactions for a spacing larger than $60 \mathrm{~m}-80 \mathrm{~m}$ in the lifetime of a geothermal reservoir (thirty years) are negligible. This is due to the very slow propagation of heat through the lowpermeability rock. However, as proven by many researches for single-fracture EGS, the fracture aperture varies during the heat production from an EGS, and the aperture variation has negative effects on the lifetime of the EGS. For the case of multiple fractures, the mechanical interaction between multiple fractures can be significant and it affects the aperture and the geometry of the propagating fractures as shown by Kumar and Ghassemi (2016) and Salimzadeh et al. (2017a) for multiple hydraulic fractures. In EGS, the thermal contraction of the matrix reduces the contact stress on the fractures in the vicinity of the cold region, and that increases the aperture of the fractures. The increase in the aperture, negatively affects the heat production from the EGS as shown by Salimzadeh et al. (2018a, b) for a single fracture EGS. The importance of coupling mechanics to the flow and transport has been demonstrated in other applications such as in $\mathrm{CO}_{2}$ sequestration by Martinez et al., (2013) and Dempsey et al. (2014), in nuclear waste disposal by Rutqvist et al. (2005) and Tsang et al. (2012), in solute transport by Nick et al. (2011), in geothermal reservoirs by McDermott et al. (2006), and in hydraulic fracturing process by Salimzadeh and Khalili (2015) and Salimzadeh et al., (2017b).

As a single fracture system has limited exposed area for heat transfer to happen between the cold fluid and the surrounding hot rock formation, a system with multiple fractures can be implemented in order to improve the performance of the EGS. Increasing the number of fractures provides several flow paths allowing the cold fluid to access a greater volume of rock. Recently, Wu et al. (2016) presented a semi-analytical thermo-hydro (TH) model for an EGS system with multiple fractures. In their model, fractures are considered to be infinite and horizontal, and a temperature gradient is considered with the assumption that the initial temperature at the bottom fracture is fixed. They have varied the spacing between fractures from 5 to $120 \mathrm{~m}$, and the number of fractures up to 13, and have shown that when the spacing between fractures reduces, the two neighbouring fractures communicate, and the heat plume of the fractures interacts. However, they suggested that when the spacing between fractures is more than $80 \mathrm{~m}$, the thermal interactions within the lifetime of the EGS (30 years) are negligible. The contribution of the mechanical deformation in the response of a singlefracture EGS is already mentioned to be important, however, for a multiple-fracture EGS, to the best knowledge of the authors, there is no studies on the thermoelastic interactions between the fractures.

In this paper, a coupled thermo-hydro-mechanical (THM) finite element (FEM) model is utilised to investigate the thermoelastic interactions between multiple fractures in an EGS. Fractures are modelled as surface discontinuities in three-dimensional matrix. Flow through fractures are modelled using cubic law, together with advective-diffusive heat transfer within fractures. The matrix is considered impermeable and the heat is propagating through conduction. The governing equations are solved numerically using Galerkin finite element method (FEM). The model has been validated and used to simulate single-, two- and threefracture EGS examples to demonstrate the importance of the mechanical coupling on energy production. 


\section{Methodology}

In this study, a model of multiple-fracture EGS is built based on the simple geometry suggested by Guo et al. (2016). In their model, a horizontal radial fracture is assumed that connects the injection and production wells as shown in Figure 1. Such geometry is created based on the geothermal field in the Cooper Basin, Australia (Chopra and Wyborn, 2003; Baisch et al., 2009; Llanos et al., 2015). Similar geometries for the EGS simulations are used by other researchers in this field (e.g. Ghassemi et al, 2011; Pandey et al., 2014). The aim is to study the extent of the mechanical interactions between multiple parallel fractures and compare it with the thermal interactions. The model includes a horizontal fracture of radius $500 \mathrm{~m}$. The domain is $3 \mathrm{~km} \times 3 \mathrm{~km} \times 3 \mathrm{~km}$, the penny-shaped fracture is located in the centre, and the injection and production wells are directly connected to the fracture, as shown in Figure 1. The distance between the injection and production wells is set to 500 meters. The initial pore pressure is set to $34 \mathrm{MPa}$, and the three principal in situ stresses (64, 70 and 100 $\mathrm{MPa}$ ) are assigned to the faces of the box-shaped model. The initial reservoir temperature at the depth of fracture is set to $200^{\circ} \mathrm{C}$. The water is injected at a constant rate of $0.0125 \mathrm{~m}^{3} / \mathrm{s}$ with a constant fluid temperature of $50^{\circ} \mathrm{C}$. Production is defined by constant pressure at the producer well; however, as the leakoff is assumed to be negligible in these simulations, the production rate rapidly reaches to the injection rate as time elapses. As there is no flow within the rock matrix, the heat propagates through conduction in the rock matrix, while within the fracture the heat is transferred mainly by advection. The material properties are given in Table 1 . The fluid density is considered to be pressure- and temperature-dependant, using the following function:

$$
\rho_{f}=\rho_{r} e^{\left[\beta_{f}\left(p_{f}-p_{r}\right)-\alpha_{f}\left(T_{f}-T_{r}\right)\right]}
$$

where $\rho_{r}=887.2 \mathrm{~kg} / \mathrm{m}^{3}, p_{r}=34 \mathrm{MPa}$, and $T_{r}=200^{\circ} \mathrm{C}$ are the reference (initial) density, pressure and temperature, respectively. The volumetric matrix thermal expansion coefficient of the solid $\left(\beta_{s}\right)$ is modified for a low permeability matrix using the expression given by McTigue (1986) for undrained thermal expansion coefficient of a fluid-saturated rock

$$
\beta_{u}=\beta_{s}+\phi B\left(\beta_{f}-\beta_{s}\right)
$$

where $\beta_{u}$ is the undrained thermal expansion coefficient of a fluid-saturated, and $B$ is the Skempton coefficient (Jaeger et al., 2007). For the given bulk modulus, porosity, and fluid compressibility used in this example, the undrained volumetric thermal expansion is $\beta_{u}=$ $3.0 \times 10^{-5} /{ }^{\circ} \mathrm{C}$.

The proposed numerical model is validated against two analytical solutions and one numerical simulation. Additional validation examples are performed in other publications by the authors, e.g. hydraulic fracturing examples (Salimzadeh et al., 2017a, b; Usui et al., 2017).

\section{Computational Model}

The fully coupled poroelastic and thermoporoelastic models for discrete fractures in a deformable medium has been presented by Salimzadeh et al. (2017a, b) and Salimzadeh et al. (2016, 2018a, b), respectively. The fully coupled governing equations for non-isothermal flow through deformable matrix with discrete fractures can be found in Salimzadeh et al., 2018a. In this section, a short review of the governing equations for impermeable matrix is 
presented. The fractures are modelled as discontinuous surfaces in the three-dimensional matrix, and a contact model is utilised to compute the contact tractions on the fracture surfaces under thermoelastic compression. Assuming impermeable rock matrix, the coupled computational model consist of four sub-models: a mechanical deformation-contact model, flow and heat transfer models for fracture, and heat transfer model for the rock matrix. The flow and heat transfer models through the fractures are defined for two-dimensional discrete fractures, while the conductive heat transfer in the rock matrix, as well as the mechanical deformation-contact model are constructed for a three-dimensional body. To reduce the computational cost, the mechanical deformation and contact tractions are solved in a mechanical deformation-contact model (M) while the flow and heat transfers are solved in a thermo-hydraulic (TH) model. The two models are coupled sequentially.

\subsection{Mechanical Deformation-Contact (M) Model}

The thermoelastic mechanical deformation model is based on the stress equilibrium for a representative elementary volume of porous medium. The linear momentum balance equation may be written as

$$
\operatorname{div} \boldsymbol{\sigma}+\mathbf{F}=0
$$

where $\mathbf{F}$ is the body force per unit volume, and $\boldsymbol{\sigma}$ is the total stress. Assuming linearity, the thermal strain within the solid rock, when the rock matrix undergoes a temperature change from initial temperature $T_{0}$ to a new value $T_{m}$, is given by Zimmerman (2000)

$$
\boldsymbol{\varepsilon}_{T}=-\boldsymbol{\alpha}_{S}\left(T_{m}-T_{0}\right)
$$

where $\boldsymbol{\alpha}_{S}$ is a symmetric second-order tensor known as the thermal expansivity tensor of the rock matrix. If the rock is isotropic then $\boldsymbol{\alpha}_{s}=\frac{1}{3} \beta_{s} \mathbf{I}$, where the scalar coefficient $\beta_{s}$ is known as the coefficient of volumetric thermal expansion of rock matrix. The stress-strain relationship for thermoelasticity can be written as (Khalili and Selvadurai, 2003)

$$
\boldsymbol{\sigma}=\mathbb{D} \boldsymbol{\varepsilon}-\beta_{s} K\left(T_{m}-T_{0}\right) \mathbf{I}
$$

in which $\mathbb{D}$ is the stiffness matrix and $K$ is bulk modulus of rock. Assuming infinitesimal deformations, strain is related to displacement by

$$
\boldsymbol{\varepsilon}=\frac{1}{2}\left(\nabla \mathbf{u}+\nabla \mathbf{u}^{T}\right)
$$

where $\mathbf{u}$ denotes the displacement vector of the rock matrix. Hydraulic loading on the fracture boundary are applied as a normal traction

$$
\boldsymbol{F}_{c}=\boldsymbol{\sigma}_{c}-p_{f} \boldsymbol{n}_{c}
$$

where $\sigma_{c}$ is the contact tractions on the fracture surfaces, $p_{f}$ is the fluid pressure inside fracture, and $\mathbf{n}_{c}$ is the outward unit normal to the fracture surface (on both sides of the fracture). The governing differential equation for mechanical deformation-contact is thus given by

$$
\operatorname{div}(\mathbb{D} \boldsymbol{\varepsilon})+\mathbf{F}=\operatorname{div}\left(\beta_{s} K\left(T_{m}-T_{0}\right) \mathbf{I}\right)+\delta\left(\mathbf{x}-\mathbf{x}_{c}\right)\left(p_{f} \mathbf{n}_{c}-\boldsymbol{\sigma}_{n}\right)
$$


where $\delta\left(\mathbf{x}-\mathbf{x}_{c}\right)$ is the Dirac delta function, and $\mathbf{x}_{c}$ represents the position of the fracture $\left(\Gamma_{c}\right)$. Note that the contact tractions and hydraulic loadings exist only on the fracture surfaces $\left(\Gamma_{c}\right)$. A sophisticated algorithm is used for the treatment of frictional contact between the fracture surfaces, based on isoparametric integration-point-to-integration-point discretisation of the contact contribution. Contact constraints are enforced by using a gap-based Augmented Lagrangian (AL) method developed specifically for fractured media (Nejati et al., 2016). In this model, penalties are defined at each timestep as a function of local aperture. The original contact model has been extended to incorporate thermoporoelastic loadings (Salimzadeh et al., 2017c).

\subsection{Coupled Thermo-Hydro (TH) Model}

\section{Fracture Flow Model}

A laminar flow is considered for fracture discontinuities. The mass balance equation for slightly compressible fluid can be expressed as (Salimzadeh and Khalili, 2016)

$$
\operatorname{div}\left(a_{f} \rho_{f} v_{f}\right)+\frac{\partial}{\partial t}\left(a_{f} \rho_{f}\right)=0
$$

where $a_{f}$ is the fracture aperture, $\rho_{f}$ is the density of fluid and $v_{f}$ is fluid velocity in the fracture. Fluid flow through a fracture is governed by the cubic law, which is derived from the general Navier-Stokes equation for flow of a fluid between two parallel plates (Zimmerman and Bodvarsson, 1996)

$$
v_{f}=-\frac{a_{f}^{2}}{12 \mu_{f}} \nabla p_{f}
$$

where $\mu_{f}$ is viscosity. The fluid density is a function of both fluid pressure and temperature and may be written as

$$
\frac{\partial \rho_{f}}{\partial t}=\rho_{f} c_{f} \frac{\partial p_{f}}{\partial t}-\rho_{f} \beta_{f} \frac{\partial T_{f}}{\partial t}
$$

where $c_{f}$ is the fluid compressibility, $T_{f}$ is the fluid temperature in the fracture, and $\beta_{f}$ is the volumetric thermal expansion coefficient of the fluid. When two surfaces of a fracture are in partial contact at the micro-scale, the mean aperture of the fracture can be written as a function of the normal contact stress. In this study, the classic Barton-Bandis model (Bandis et al., 1983; Barton et al., 1986) is used to calculate the fracture aperture under contact stress

$$
a_{f}=a_{0}-\frac{a \sigma_{n}}{1+b \sigma_{n}}
$$

where $\sigma_{n}$ is the normal component of the contact stress, $a_{0}$ is the fracture aperture at zero contact stress, and $a$ and $b$ are model parameters. The normal contact stress is directly computed in the mechanical deformation-contact model $(\mathrm{M})$. In the fracture flow model, the change in aperture can be approximated from the change in the fluid pressure in the fracture as

$$
\frac{\partial a_{f}}{\partial t}=\frac{1 \partial p_{f}}{K_{n} \partial t}
$$

in which $K_{n}$ is the fracture tangent stiffness, given by 


$$
K_{n}=-\frac{\partial \sigma_{n}}{\partial a_{f}}=\frac{\left(1+b \sigma_{n}\right)^{2}}{a}
$$

234 The governing equation for the laminar flow in the fracture is written as

$$
\operatorname{div}\left(\frac{a_{f}^{3}}{12 \mu_{f}} \nabla p_{f}\right)=\left(\frac{1}{K_{n}}+a_{f} c_{f}\right) \frac{\partial p_{f}}{\partial t}-a_{f} \beta \frac{\partial T_{f}}{\partial t}
$$

\section{Fracture Heat Transfer Model}

The heat transfer model in the fracture is achieved by combining Fourier's law with the energy balance for fluid. The advective-diffusive heat transfer flux through the fracture fluid may be written as (Salimzadeh et al., 2016)

$$
q_{f c}=-a_{f} \lambda_{f} \nabla T_{m}+a_{f} \rho_{f} C_{f} \mathbf{v}_{f} T_{f}
$$

where $\lambda_{f}$ is the thermal conductivity tensor of the fluid, $T_{f}$ is the fluid temperature, $C_{f}$ is the specific heat capacity of the fluid. The heat energy change due to thermal power in the course of the bulk deformation of fluid can be expressed as

$$
q_{f p}=a_{f} \beta_{f} T_{f} \frac{\partial p_{f}}{\partial t}
$$

Heat is also exchanged between matrix and fracture fluid by conduction through the fracture surfaces. The heat leakoff can be defined as a function of the thermal conductivity of the matrix and the temperature gradient at the fracture surfaces

$$
q_{m f}=\lambda_{n} \frac{\partial T}{\partial \mathbf{n}_{c}}
$$

where $\lambda_{n}$ is the thermal conductivity of the rock matrix along the direction normal to the fracture (in the direction of $\mathbf{n}_{c}$ ). The rate of heat storage in the fluid is given by

$$
q_{f s}=a_{f} \rho_{f} C_{f} \frac{\partial T_{f}}{\partial t}
$$

The governing equation for the heat transfer through the fluid in the fracture can be written as

$$
\operatorname{div}\left(a_{f} \lambda_{f} \nabla T_{f}\right)=a_{f} \rho_{f} C_{f} \frac{\partial T_{f}}{\partial t}-a_{f} \beta_{f} T_{f} \frac{\partial p_{f}}{\partial t}+a_{f} \rho_{f} C_{f} \mathbf{v}_{f} \cdot \nabla T_{f}-\lambda_{n} \frac{\partial T}{\partial \mathbf{n}_{c}}
$$

\section{Matrix Heat Transfer Model}

The matrix is assumed to be impermeable so the heat transfer occurs only through conduction. The conductive heat flux can be written as

$$
q_{m c}=-\lambda_{m} \nabla T_{m}
$$

where $\lambda_{m}$ is the thermal conductivity tensor of the matrix, and $T_{m}$ is the matrix temperature. The thermal conductivity tensor for the medium saturated by a fluid is calculated as a function of the fraction between solid and fluid (for more accurate models of the effective thermal conductivity see Zimmerman, 1989)

$$
\lambda_{m}=(1-\phi) \lambda_{s}+\phi \lambda_{f}
$$


The rate of heat storage in the matrix is a function of the average density and specific heat capacity of the saturated matrix, and it may be written as

$$
q_{m s}=\rho_{m} C_{m} \frac{\partial T_{m}}{\partial t}
$$

where $\rho_{m} C_{m}$ can be computed (exactly) from the density and specific heat capacity values of rock solid $\left(\rho_{s}, C_{s}\right)$ and fluid $\left(\rho_{f}, C_{f}\right)$ as

$$
\rho_{m} C_{m}=(1-\phi) \rho_{s} C_{s}+\phi \rho_{f} C_{f}
$$

The governing equation for heat transfer within the matrix is thus given by

$$
\operatorname{div}\left(\boldsymbol{\lambda}_{m} \nabla T_{m}\right)=\left(\rho_{m} C_{m}-\beta_{s}^{2} K T_{m}\right) \frac{\partial T_{m}}{\partial t}+\delta\left(\mathbf{x}-\mathbf{x}_{c}\right) \lambda_{n} \frac{\partial T}{\partial \mathbf{n}_{c}}
$$

Note that the heat leakoff only occurs through the fracture surfaces $\left(\Gamma_{c}\right)$. To reduce computational time, the mechanical contact model $(\mathrm{M})$ is solved separately from the rest of the TH model. However, they are still coupled iteratively, where the following process is carried out in each timestep. Firstly, the TH model is run with contact stresses and fracture aperture computed from the previous step (or initial values for the first step). The TH model then sends the computed temperatures and pressures values to the mechanical contact model so the results for the contact stresses and fracture aperture can be updated. Further, the TH model is ran with the updated apertures. The contact model is run in the "stick" mode, which means that sliding along the opposing fracture surfaces is not allowed.

\subsection{Finite Element Approximation}

The governing equations are solved numerically using the finite element method. The Galerkin method and finite difference techniques are used for spatial and temporal discretisation, respectively. The displacement vector $\mathbf{u}$ is defined as the primary variable in the mechanical deformation-contact model $(\mathrm{M})$, whereas the fluid pressure $p_{f}$, and fracture fluid and matrix temperatures $T_{f}$ and $T_{m}$, are defined as the primary variables in the TH model. Using the standard Galerkin method, the displacement vector $\mathbf{u}$, fluid pressure $p_{f}$ and fluid and solid temperatures $T_{m}$ and $T_{f}$ within an element are defined as a function of their nodal values $\left(\hat{\mathbf{u}}, \hat{p}_{f}, \hat{T}_{f}, \hat{T}_{m}\right)$ as

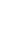

$\begin{aligned} \mathbf{u} & =\mathbf{N} \hat{\mathbf{u}} \\ p_{f} & =\mathbf{N}_{c} \hat{\mathbf{p}}_{f} \\ T_{f} & =\mathbf{N}_{c} \hat{\mathbf{T}}_{f} \\ T_{m} & =\mathbf{N} \hat{\mathbf{T}}_{m}\end{aligned}$

where $\mathbf{N}$ and $\mathbf{N}_{c}$ are the vector of shape functions for matrix (3D) and fracture (2D), respectively. Using the finite difference technique, the time derivative of $\mathbb{X}$ is defined as

$$
\frac{\partial \mathbb{X}}{\partial t}=\frac{\mathbb{X}^{t+d t}-\mathbb{X}^{t}}{d t}
$$

where $\mathbb{X}^{t+d t}$ and $\mathbb{X}^{t}$ are the values of $\mathbb{X}$ at time $t+d t$ and $t$, respectively. The set of discretised equations can be written in matrix form as $\mathbb{S X}=\mathbb{F}$, in which $\mathbb{S}$ is the element's 
301

302

303

304

305

306

307

308

309

310

311

312

313

314

315

316

317

318

319

320

321

322

general stiffness matrix, and $\mathbb{F}$ is the vector of right-hand-side loadings. For the mechanical deformation-contact model (M) the set of discretised equations may be written in matrix form as

$$
\left[\mathbb{S}_{u u}\right][\hat{\mathbf{u}}]=\left[\mathbf{F}+\boldsymbol{C}_{p_{f}} \hat{\mathbf{p}}_{f}+\boldsymbol{C}_{T_{m}}\left(\hat{\mathbf{T}}_{m}-\hat{\mathbf{T}}_{0}\right)\right]
$$

and for the TH model

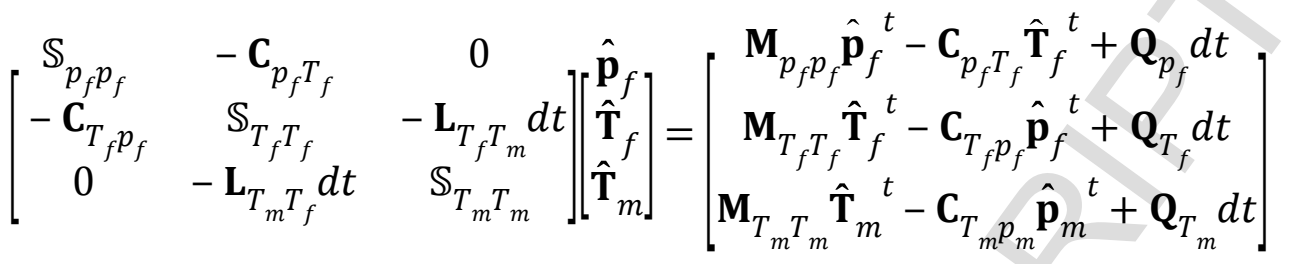

where

$$
\mathbb{S}_{u u}=\int_{\Omega} \bar{\nabla} \mathbf{N}^{T} \mathbb{D} \bar{\nabla} \mathbf{N} d \Omega
$$

$$
\mathbb{S}_{T_{f} T_{f}}=\mathbf{H}_{T_{f}} d t+\mathbf{M}_{T_{f} T_{f}}+\mathbf{L}_{T_{m} T_{f}} d t
$$

$$
\mathbf{H}_{T_{f}}=\int_{\Gamma_{c}} \nabla \mathbf{N}_{c}^{T} a_{f} \lambda_{f} \nabla \mathbf{N}_{c} d \Gamma+\int_{\Gamma_{c}} \mathbf{N}_{c}^{T} a_{f} \rho_{f} C_{f} \mathbf{v}_{f} \nabla \mathbf{N}_{c} d \Gamma
$$

$$
\mathbf{H}_{T_{m}}=\int_{\Omega} \nabla \mathbf{N}^{T} \lambda_{m} \nabla \mathbf{N} d \Omega
$$

where $\mathbf{Q}$ represents the flow and heat rate vectors, superscript $t$ represents the time at the current time step, superscript $t+d t$ represents time at the next time step, and $d t$ is the timestep. The non-diagonal components of the stiffness matrix $\mathbb{S}$ are populated with the 
coupling matrices $\mathbf{C}$, and $\mathbf{L}$. Note that the leakoff term only exists for matrix elements (volume elements) connected to a fracture; it is evaluated over the surface of the volume element that is shared with the fracture, and is equal to zero for other faces of that element. The gradient matrix $\bar{\nabla}$ for three-dimensional displacement field is defined as

$$
\bar{\nabla}=\left|\begin{array}{ccc}
\frac{\partial}{\partial x} & 0 & 0 \\
0 & \frac{\partial}{\partial y} & 0 \\
0 & 0 & \frac{\partial}{\partial z} \\
0 & \frac{\partial}{\partial z} & \frac{\partial}{\partial y} \\
\frac{\partial}{\partial z} & 0 & \frac{\partial}{\partial x} \\
\frac{\partial}{\partial y} & \frac{\partial}{\partial x} & 0
\end{array}\right|
$$

The components of the stiffness matrix are dependent upon the primary unknown variables, i.e. conductance, capacitance and coupling coefficients of the fracture are all dependent on the fracture aperture; therefore, a Picard iteration procedure is adopted to reach the correct solution within acceptable tolerance. For current iteration $s+1$ in current step $n+1$, the solution-dependent coefficient matrices in the stiffness matrix $\mathbb{S}$ are updated using weighted average solution vector $\mathbb{X}_{n+1}^{s+\theta}$ defined as

$$
\mathbb{X}_{n+1}^{s+\theta}=(1-\theta) \mathbb{X}_{n+1}^{s-1}+\theta \mathbb{X}_{n+1}^{s}
$$

where $\mathbb{X}_{n+1}^{s-1}$ and $\mathbb{X}_{n+1}^{s}$ are the solution vectors of the two most recent iterations in the current timestep $n+1$, and $\theta=2 / 3$ is the weighting coefficient. For the first iteration $s=1$, the previous timestep solution is used as

$$
\mathbb{X}_{n+1}^{0}=\mathbb{X}_{n+1}^{1}=\mathbb{X}_{n}
$$

where $\mathbb{X}_{n}$ is the solution vector from previous timestep $n$. The iterations are repeated until consecutive normalised values of $\mathbb{X}_{n+1}^{s}$ agree to within a specified tolerance $\varepsilon$

$$
\frac{\left\|\mathbb{X}_{n+1}^{s+1}-\mathbb{X}_{n+1}^{s}\right\|}{\left\|\mathbb{X}_{n+1}^{s+1}\right\|}<\varepsilon
$$

The tolerance is set to $1 \%$. The discretised equations are implemented in the Complex Systems Modelling Platform (CSMP++), a finite element base code library (Matthäi et al., 2001) designed to simulate complex multi-physics problems of geological processes (e.g. Matthäi et al., 2010; Nick and Matthäi, 2011; Paluszny and Zimmerman, 2011). Quadratic tetrahedra are used for spatial discretisation of volumes and quadratic triangles for surfaces. For the fracture, the triangles on the two opposite surfaces match to each other, while the nodes are not shared but rather duplicated for the two sides. The triangles are matched with faces of the tetrahedra connected to the fractures, where they also share the same nodes. Fracture flow and fracture heat equations are accumulated only on one side of the fracture, whereas, the heat leakoff is accumulated over both sides of the fracture. The ensuing set of 
linear algebraic equations $\mathbb{S X}=\mathbb{F}$ is solved at each timestep using the algebraic multigrid method for systems, SAMG (Stüben, 2001).

\section{Model Validation}

\section{One-dimensional flow through a rigid fracture}

In this example, a fracture of length $1 \mathrm{~km}$ is considered between injection and production wells, as shown in Figure 2a. Plane-strain conditions are assumed, in order to validate the model results against the analytical solution given by Bodvarsson (1969) as

$$
T_{d}(x, y, t)=\operatorname{erfc}\left[\left(\frac{\lambda_{s} x}{q \rho_{w} C_{w}}+\frac{y}{2}\right) \sqrt{\frac{\rho_{s} C_{s}}{\lambda_{s} t}}\right]
$$

in which, $T_{d}=\left(T_{0}-T\right) /\left(T_{0}-T_{i n j}\right), T_{0}$ is the initial temperature, and $T_{i n j}$ is the temperature of the injected fluid. Injection of cold water at temperature $20^{\circ} \mathrm{C}$, at constant rate $q=0.0001$ $\mathrm{m}^{2} / \mathrm{s}$ is assumed, while production is simulated through constant zero pressure in the production well. The initial temperature of the rock matrix is set to $100{ }^{\circ} \mathrm{C}$. Water has a density of $\rho_{f}=1000 \mathrm{~kg} / \mathrm{m}^{3}$, a heat capacity of $C_{f}=4200 \mathrm{~J} / \mathrm{kg}{ }^{\circ} \mathrm{C}$, and the matrix rock has density $\rho_{s}=2820 \mathrm{~kg} / \mathrm{m}^{3}$, heat capacity of $C_{s}=1170 \mathrm{~J} / \mathrm{kg}{ }^{\circ} \mathrm{C}$, and thermal conductivity of $\lambda_{s}=$ $2.88 \mathrm{~W} / \mathrm{m}{ }^{\circ} \mathrm{C}$. Constant matrix temperature is assumed at the far boundaries of the simulation region, while the matrix is assumed impermeable to the flow, so the injected fluid remains inside the fracture, while the heat is transferred through conduction in the matrix. A box model of size $5000 \times 1000 \times 10000 \mathrm{~m}$ is built and spatially discretised using 25,248 quadratic tetrahedral and triangular elements. The results for the fluid temperature at production are shown in Figure 2b. Included in these figure is the solution proposed by Bodvarsson (1969) for comparison. The temperature of the cold water in the fracture increases as it exchanges heat with the hot rock matrix. Very good agreement is found between the present model results and the solution proposed by Bodvarsson (1969).

\section{Radial flow through a rigid fracture}

In this example, an infinite fracture is modelled, and the cold water is injected into the centre of the fracture. The matrix is assumed impermeable to the flow, so the heat is being transferred only through conduction in the matrix. Ghassemi et al. (2003) presented the analytical solution for the temperature of the matrix as

$$
T_{d}(x, y, t)=\operatorname{erfc}\left[\left(\frac{\pi \lambda_{s} x^{2}}{Q \rho_{w} C_{w}}+\frac{y}{2}\right) \sqrt{\frac{\rho_{s} C_{s}}{\lambda_{s} t}}\right]
$$

A fracture of $3000 \mathrm{~m} \times 3000 \mathrm{~m}$ is modelled in a block of $3 \mathrm{~km} \times 3 \mathrm{~km} \times 3 \mathrm{~km}$ as shown in Figure 2c. The model is discretised spatially using 32,984 quadratic tetrahedral and triangular elements. The injection rate is set to $Q=0.01 \mathrm{~m}^{3} / \mathrm{s}$, water has a density of $\rho_{f}=1000 \mathrm{~kg} / \mathrm{m} 3$, a heat capacity of $C_{f}=4200 \mathrm{~J} / \mathrm{kg}{ }^{\circ} \mathrm{C}$, the matrix rock has density $\rho_{s}=2700 \mathrm{~kg} / \mathrm{m} 3$, heat capacity of $C_{s}=1000 \mathrm{~J} / \mathrm{kg}{ }^{\circ} \mathrm{C}$, and thermal conductivity of $\lambda_{s}=2.0 \mathrm{~W} / \mathrm{m}{ }^{\circ} \mathrm{C}$. The results for the temperature profile at three timesteps: $t=10^{7}, 10^{8}$, and $10^{9} \mathrm{~s}$ are shown in Figure $2 \mathrm{~d}$. Very good match is observed between the present model and the analytical results. 


\subsection{A Single-fracture EGS}

For further validation, the example given by Guo et al. (2016) is adopted and the results of the present model is compared against their results for the homogenous aperture field. In this example, heat is produced from a horizontal penny-shaped fracture in a low-permeability hot crystalline rock, which roughly resembles the Habanero project in the Cooper Basin, Australia (Chopra and Wyborn, 2003; Baisch et al., 2009; Llanos et al., 2015). The fracture aperture is defined as a function of the contact stress, using the Barton-Bandis model (Eq. 12). Two reference points are assumed to evaluate the model parameters $a$ and $b$, where the fracture aperture at zero contact stress $a_{0}$ is assumed equal to $a / b$. The two reference points are: $a_{f}=0.24 \mathrm{~mm}$ for $\sigma_{n}=30 \mathrm{MPa}$, and $a_{f}=0.72 \mathrm{~mm}$ for $\sigma_{n}=5 \mathrm{MPa}$. For these given data, the model parameters $a$ and $b$ are $1.6 \times 10^{-10} / \mathrm{Pa}$ and $1.333 \times 10^{-7} / \mathrm{Pa}$, respectively. The domain is discretised spatially using 39,957 quadratic tetrahedra and triangles for matrix volume and fracture surface, respectively. The mesh is refined at the injection and production points as shown in Figure 3a. The first timestep is set to 1 day, and in each step the timestep is increased by a factor of 1.1 until the prescribed maximum timestep of 0.25 years is reached. The cold plume around the fracture at the end of simulation is shown in Figure $3 \mathrm{~b}$. The temporal variation of the temperature of the water produced at the production well is shown in Figure 3c. A very good agreement is found between the results from the present model and the results by Guo et al. (2016), which validates the accuracy of the present model and the choice of mesh.

The given parameters in Table 1 are for a crystalline rock, so sensitivity analyses are performed in which the Young's modulus and the matrix porosity have been altered to 20 $\mathrm{GPa}$ and 0.2 to represent a sandstone reservoir. The results for the aperture evolution within the fracture at time 5, 15 and 30 years of simulation, together with its temperature at 30 years are plotted for three various scenarios in Figure 4. Lower Young's modulus reduces the stresses developed during the contraction of the matrix, and results in lower fracture aperture, and thus slower drawdown of the production temperature as the cold fluid gets access to a larger area of the fracture. For a stiffer rock on the other hand, higher fracture aperture is observed near the injection well and towards the production well, which advances the channelling between the two wells, resulting in a faster reduction in the temperature of the produced water. For the softer rock $(E=20 \mathrm{GPa})$, however when the porosity in the rock matrix is increased to 0.2 , the fracture aperture increases compared to the case with lower porosity. This is related to the higher undrained thermal expansion coefficient for the higher matrix porosity. Higher undrained thermal expansion coefficient improves the mechanical effects and as a result, the rock contracts more and aperture increases more as shown in Figure 4. Higher aperture provides improved flow path between the injector and producer wells and the cold fluid reaches the producer well faster. The produced temperature and aperture distribution for the case of sandstone reservoir with a high porosity (0.2) is similar to those of the granite reservoir with a very low porosity $(0.01)$. Not that there is no flow in the matrix, and the effect of the change in porosity is applied through the undrained thermal expansion coefficient of the matrix.

\section{Multiple-Fracture EGS}

\subsection{Two-Fracture EGS}

In this section, we aim at investigating the effect of the mechanical interactions between fractures on the response of the EGS system. As shown in Figure 5a, a model with two 
parallel fractures is built by adding a second fracture to the model presented in the previous section. The spacing between the two fractures ranges from $50 \mathrm{~m}$ to $1000 \mathrm{~m}$, and the temperature at the bottom fracture is fixed at $200{ }^{\circ} \mathrm{C}$. The model is discretised spatially using between 58,413 and 74,813 quadratic elements (depending on the geometry). The fixed temperature at the bottom fracture enables the comparison of the two-fracture system with the single-fracture system presented in the previous section. When the vertical thermal gradient is considered, the temperature reduces as the top fracture moves up. Constant flow rate of $0.0125 \mathrm{~m}^{3} / \mathrm{s}$ is applied to each fracture. Note that the life time is determined for a minimal production temperature of $140{ }^{\circ} \mathrm{C}$. Depending on the usage of the produced hot water and if we take future technical development into consideration the minimal production temperature could be lower (Willems et al., 2017).

\section{Uniform initial temperature}

Firstly, a system with uniform temperature at $200{ }^{\circ} \mathrm{C}$ is simulated to identify when the mechanical interaction starts to affect the output temperature. As the fractures are positioned symmetrically in the domain, both fractures show equal aperture when the system has a uniform in situ temperature. To look at the mechanical interactions, the vertical stress experienced in the middle of the two fractures for the system with $\mathrm{E}=50 \mathrm{GPa}$ (white line in Figure $5 \mathrm{~b}$ ) is plotted for fracture spacing of $1000 \mathrm{~m}, 750 \mathrm{~m}$ and $500 \mathrm{~m}$ in Figure $5 \mathrm{c}$. The areas not affected by the mechanical interaction has a value equal to the initial vertical stress, 64 $\mathrm{MPa}$. For a spacing of $1000 \mathrm{~m}$, the minimum effective stress in the centre of the model is found to be $61.56 \mathrm{MPa}$, indicating a stress change of $2.44 \mathrm{MPa}(3.81 \%$ decrease). The minimum vertical stress at this location reduces to about $53 \mathrm{MPa}$ for spacing of $500 \mathrm{~m}(17 \%$ reduction in vertical stress). The changes in the vertical stresses affect the aperture in the fractures and lower vertical stress results in higher aperture. The contours for the vertical stress around the fractures are shown in Figure 5d. It can be observed that the mechanical interactions have already started between the two fractures with $500 \mathrm{~m}$ spacing, while the thermal interactions are almost negligible at these spacing.

The production temperature for two cases of Young's modulus $E=50 \mathrm{GPa}$ and $E=20 \mathrm{GPa}$ (granite and sandstone reservoirs) are shown in Figure 6. A good fit is observed between the fracture spacing of $750 \mathrm{~m}$ for $E=50 \mathrm{GPa}$ and the single fracture model, indicating that the mechanical interactions between the two fractures at this spacing are negligible. For the softer rock with $E=20 \mathrm{GPa}$, the spacing of $500 \mathrm{~m}$ also shows a good fit with the single fracture results. Therefore, the extent of mechanical interactions reduces for lower Young's modulus, however, this spacing is still much higher than the extent of the thermal interactions reported by $\mathrm{Wu}$ et al. (2016). When the spacing is further reduced, a change in the breakthrough curve is realised which indicate that the mechanical interactions between fractures are affecting the apertures and as such reducing the residence time of the fluid in fracture. The consequence of reducing the spacing can be observed through the descending slope in the production temperature in Figure 6. As the two fractures gets closer to each other, the fracture aperture increases due to the stress relaxation it receives from the neighbour fracture. An increase in fracture aperture leads to higher fluid velocity within the fracture, thus a faster drawdown in the production temperature. As the area below the temperature graph represent the amount of heat produced, it is easily seen that a spacing of $50 \mathrm{~m}$ results in a sharp reduction at the production temperature and thereby the least energy produced. Included in Figure 6a, are the simulation cases without the mechanical interactions. It can be seen that the thermal interactions between the two fractures start when the spacing decreases to less than $100 \mathrm{~m}$. Such spacing is compatible with the maximum spacing reported by Wu et al. (2016). 


\section{Initial temperature gradient}

The fractures are considered horizontal in these simulations, so to achieve more realistic results, a temperature gradient is introduced to the system. As the output temperature (at the production well) is different for the two fractures, an average value of these two is selected as the new production temperature. Ideally, the distance between the fractures should be large enough to prevent thermal and mechanical interaction from the neighbour fracture. However, the fracture spacing cannot be too wide either as the initial temperature for the top fracture reduces by increasing the spacing. In this section, a temperature gradient of $47^{\circ} \mathrm{C} / \mathrm{km}$ is introduced to the system with $\mathrm{E}=50 \mathrm{GPa}$, where the initial temperature at the bottom fracture is kept constant at $200^{\circ} \mathrm{C}$. However, lower temperature gradients may be observed in other cases $\left(\right.$ e.g. $27^{\circ} \mathrm{C} / \mathrm{km}$ used by Saeid et al., 2015). Figure 7 shows the temperature profile after 10 years of production on a vertical cross section for the spacing of $50 \mathrm{~m}, 300 \mathrm{~m}$ and $1000 \mathrm{~m}$. The interaction between the temperature plumes is only observed for the spacing of $50 \mathrm{~m}$, while the other two cases show no such interactions. This is compatible with the results by $\mathrm{Wu}$ et al. (2016) which indicated that the spacing of larger than $80 \mathrm{~m}$ is too large for thermal (and not the mechanical) interactions. As the spacing increases, the initial temperature at the top fracture reduces. In Figure 8a, the temperature profile for different spacing is plotted. Due to the initial temperature gradient, the initial average temperature reduces with increasing spacing. As the initial temperature at the bottom fracture is kept constant and equal to $200{ }^{\circ} \mathrm{C}$ for all cases, the initial temperature of the top fracture, for instance in the spacing of $1000 \mathrm{~m}$, reduces to $153{ }^{\circ} \mathrm{C}$. So, the case with minimum spacing of $50 \mathrm{~m}$ shows higher initial production temperature of $198.8^{\circ} \mathrm{C}$, while the case with $1000 \mathrm{~m}$ spacing shows an initial production temperature of $176.5^{\circ} \mathrm{C}$. However, as the mechanical interactions affect the apertures, the cases with lower spacing show higher reduction in the production temperature. The mechanical interactions in the case of $50 \mathrm{~m}$ spacing causes a rapid reduction in the output temperature such that it reaches the reference temperature of 140 ${ }^{\circ} \mathrm{C}$ in about 7 years, while the case with $1000 \mathrm{~m}$ spacing reaches this temperature after 11.5 years. The case of $500 \mathrm{~m}$ spacing shows longer production time. The fracture aperture at the injection well is plotted in Figure $8 \mathrm{~b}$ for spacing of $50 \mathrm{~m}, 150 \mathrm{~m}, 300 \mathrm{~m}$ and $1000 \mathrm{~m}$. Lower spacing shows higher aperture due to the mechanical contraction of the neighbour fracture. Due to the initial temperature gradient, the top fracture undergoes lower temperature drawdown and thus shows lower aperture. The difference between apertures in bottom and top fractures increases with increasing spacing.

Another case with lower initial temperature gradient of $30{ }^{\circ} \mathrm{C} / \mathrm{km}$ (e.g West Netherlands Basin, Bonté et al., 2012; Willems et al. 2017) is simulated where all other parameters are kept the same. The results for production temperature for different spacing are shown in Figure 9 for both temperature gradients. The initial temperature at the bottom fracture for both cases is set at $200^{\circ} \mathrm{C}$. The effect of the change in temperature gradient increases as the fracture spacing increases. A big difference is seen for the spacing of $1000 \mathrm{~m}$, while the effect is negligible for the spacing of $50 \mathrm{~m}$. The difference in initial production temperature between two temperature gradients for the spacing of $50 \mathrm{~m}$ is only $0.4{ }^{\circ} \mathrm{C}$, while a spacing of $1000 \mathrm{~m}$ will experience a temperature difference of $8.5^{\circ} \mathrm{C}$. Lower temperature gradient increases the energy extraction from the system for higher spacing as the top fracture would have higher initial temperature compared to the higher temperature gradient case.

\section{The effect of matrix deformability}

The matrix deformability affects the mechanical interactions between the two fractures as shown for the uniform temperature case in Figure 6. Softer rock shows lower mechanical 
interactions and therefore, produces hotter fluid for an extended period. When the initial temperature gradient is considered, it is shown that for lower spacing cases there is a competition between high mechanical interactions with higher initial temperature. So, the system with lower spacing starts producing water at a higher temperature, but due to the higher mechanical interactions the temperature at the production decreases faster. In this section, the case with lower Young's modulus of $E=20 \mathrm{GPa}$ is simulated with initial temperature gradient of $47{ }^{\circ} \mathrm{C} / \mathrm{km}$. The plume of the stresses around the fractures for both Young's moduli of $20 \mathrm{GPa}$ and $50 \mathrm{GPa}$, and spacing of $300 \mathrm{~m}$ and $500 \mathrm{~m}$ are shown in Figure 10. Interactions between two fractures can be seen by the interference of the stress plume. For the stiffer fracture, the two fractures are interacting when the spacing is $500 \mathrm{~m}$ while for the softer rock that spacing is large enough to neglect the interactions. When the spacing is reduced to $300 \mathrm{~m}$, the stress interactions are considerable even for the softer rock. The bottom fracture also shows higher stress reduction due to higher temperature variation. The production temperatures for different spacing are shown in Figure 11a. As the mechanical interactions are lower for the $E=20 \mathrm{GPa}$, the simulations for spacing of $40 \mathrm{~m}$ and $35 \mathrm{~m}$ are added. For the softer rock, the mechanical interaction between two fractures reduces therefore, this system produces hotter fluid for longer time. However, as shown in Figure 11a, the lower spacing induces higher mechanical interactions and therefore higher aperture in the fracture and faster reduction of the production temperature, while higher spacing shows lower initial production temperature and lower reduction of the temperature versus time. As a result, the curves for lower spacing cross the ones for higher spacing. The production temperature for two cases of Young's moduli with spacing of $50 \mathrm{~m}$ and $1000 \mathrm{~m}$ are compared in Figure 11b. Lower Young's modulus reduces the mechanical interactions so the case with $50 \mathrm{~m}$ spacing crosses the curve with $1000 \mathrm{~m}$ spacing after 15 years of production, while for the stiffer rock, the crossing occurs much earlier (around 6 years). The slope of the production temperature for the case of stiffer rock is also higher than the softer rock for the $1000 \mathrm{~m}$ spacing. Although, for spacing of $1000 \mathrm{~m}$, it is shown earlier that the mechanical interactions between two fractures are negligible for both Young's moduli, so the higher temperature drop is the result of the ability of the stiff matrix in sustaining higher aperture as shown in Figures $11 \mathrm{c}$ and $11 \mathrm{~d}$. The aperture in the softer rock is much less than the stiff rock for all spacing. When the spacing is reduced in softer rock, the aperture initially increases, however, due to the redistribution of stresses, the soft rock is not able to sustain high apertures and therefore the aperture approaches to a maximum value. Due to lower fracture aperture in the softer rock, the cold fluid can access to higher area of the fracture as shown before in Figure 4a for single fracture case. The vertical stress reduces over a larger area of the fracture in softer rock compared with stiffer rock as shown in Figure 12. The stiffer rock sustains higher reduction in the vertical stress (and higher aperture) and the additional load is carried by the area around the cooled area in the fracture shown in darker colour in Figure 12.

The results from the simulator highlights the importance of the thermoelastic interaction between two fractures and neglecting such interactions results in much lower optimum spacing as reported by $\mathrm{Wu}$ et al. (2016). The present observations conclude that the aperture variation highly affects the output temperature in the fracture, and the variation in the fracture aperture is a result of the thermo-mechanical interaction within the system. By assuming a constant fracture aperture, the deformation due to thermal contraction and mechanical interaction is neglected. Since the effects of mechanical interaction have been observed in a much greater spacing than the thermal interaction, the mechanical affects seems to be the most critical and the optimum spacing is rather dictated by the thermoelastic deformations. 
In this section, the radius of the fracture is reduced to $R=250 \mathrm{~m}$, to investigate how the size of the fracture affects the mechanical interactions between the two parallel fractures. The flow rate is also proportionally reduced to $Q=0.00625 \mathrm{~m}^{3} / \mathrm{s}$ to avoid early breakthrough of the cold fluid at production. A uniform temperature of $200{ }^{\circ} \mathrm{C}$ is assumed throughout the model. A set of simulations with different spacings: $D=25 \mathrm{~m}, 50 \mathrm{~m}, 75 \mathrm{~m}, 150 \mathrm{~m}$, and $250 \mathrm{~m}$ are performed with and without the mechanical interactions (using TH and THM models). The results for the temperature breakthrough at the production are shown in Figure 13 for different cases. Again, in the absence of the mechanical interactions (TH model), the two fractures are thermally interacting when the spacing decreases to less than $100 \mathrm{~m}$, while in the presence of the mechanical interactions (THM model) the thermal interactions between the two fractures affect the produced temperature from a spacing of $D=250 \mathrm{~m}$. In the TH model, a spacing of $D=150 \mathrm{~m}$ returns the temperature same as the single fracture case, indicating no thermal interactions between the two fractures. In the THM model, from a spacing of $250 \mathrm{~m}$, the two fractures are mechanically interacting, resulting in higher aperture in each fracture and thus, faster drawdown in the temperature of the produced water. Comparing with the case with bigger fracture $(\mathrm{R}=500 \mathrm{~m})$ it can be seen that the mechanical interactions between the two fractures are dependent on the size of the fractures, as larger fracture creates larger disturbance area around it. However, as the spacing decreases to the fracture radius $(D \leq R)$, the mechanical interactions start to affect the temperature drawdown.

\subsection{Three-Fracture EGS}

In this section, a third fracture is added to the model shown in Figure 5a. This is just to show how the mechanical interactions increase as the number of fractures increases. Two cases are simulated where the uniform spacing between the three fractures are set to $500 \mathrm{~m}$ and $300 \mathrm{~m}$, and the temperature at the bottom fracture is again fixed at $200{ }^{\circ} \mathrm{C}$. The initial temperature gradient is set at $47^{\circ} \mathrm{C} / \mathrm{km}$, and the flow rate is kept constant at $0.0125 \mathrm{~m}^{3} / \mathrm{s}$ for all fractures. The aperture distribution on each fracture for both cases are shown in Figure 14a. For the spacing of $150 \mathrm{~m}$, the middle fracture undergoes highest aperture increase due to the matrix contraction it receives from both sides, while the top fracture has the lowest aperture increase due to the lower initial temperature. However, for the spacing of $300 \mathrm{~m}$, the bottom fracture shows higher aperture due to higher temperature variation, and again the top fracture shows the lowest aperture variation. So, for the spacing of $300 \mathrm{~m}$, the mechanical contractions received by the middle fracture are lower to compensate for the lower initial temperature, while for the spacing of $150 \mathrm{~m}$, the mechanical contractions are quite strong for the middle fracture. The average production temperature for both cases are compared with the twofracture system in Figure 14b. The three-fracture results show lower initial production temperature due to lower initial temperature for the top fracture, also the temperature declines faster for the three-fracture case with spacing of $150 \mathrm{~m}$, due to higher mechanical interactions exerted on the middle fracture. Whereas for the spacing of $300 \mathrm{~m}$, the slope of the threefracture case is slightly lower than that of two-fracture case, perhaps due to having access to larger volume of the rock. The apertures along the horizontal line passing through the injection and production points of each fracture are plotted in Figure 14c. Lower spacing results in higher aperture around the injection point and towards the production point. For the spacing of $150 \mathrm{~m}$, middle fracture shows the highest aperture developed due to the combined thermal and mechanical contractions. For the spacing of $300 \mathrm{~m}$, the bottom fracture shows highest aperture due to the highest thermal contractions. 
621

622

623

624

625

626

627

628

629

630

631

632

633

634

635

636

637

638

639

640

641

642

643

644

645

646

647

648

649

650

651

652

653

654

655

656

\section{Net Energy Production}

The net energy production in the system is crucial as it estimate the performance of the EGS, and is determined by the sum of the energy produced minus the energy consumed by injection pump

$$
E_{n e t}=E_{g}-E_{p}
$$

The energy produced from the production well may be written as (Willems et al., 2017)

$$
E_{g}=\rho C_{f} Q \int_{t=0}^{L T}\left(T-T_{\min }\right) d t
$$

where $Q$ is the production flow rate, $T_{\text {min }}$ is the minimum temperature the plant sees it economical to produce, and $L T$ is the lifetime for when the produced temperature reaches to $T_{\text {min }}$. So, the production energy is basically the area between the production temperature and the minimum temperature. The minimum temperature is set to $140{ }^{\circ} \mathrm{C}$, indicating that the system allows a $30 \%$ drop in temperature. Energy used to pump in the injection fluid may be written as

$$
E_{p}=\int_{t=0}^{L T} \frac{Q \Delta P}{\dot{\varepsilon}} d t
$$

where $\Delta P$ is the pressure change between injector and producer, and $\varepsilon$ is the energy conversion efficiency factor, that is assumed to be 0.7 . The pumping energy is basically the area between the injection pressure and the production pressure $(34 \mathrm{MPa})$. The net energy production for the two-fracture EGS is shown in Figure 15a for three cases: (i) E $=50 \mathrm{GPa}$ and thermal gradient of $47^{\circ} \mathrm{C} / \mathrm{km}$, (ii) $\mathrm{E}=50 \mathrm{GPa}$ and thermal gradient of $30^{\circ} \mathrm{C} / \mathrm{km}$, and (iii) $\mathrm{E}=20 \mathrm{GPa}$ and thermal gradient of $47^{\circ} \mathrm{C} / \mathrm{km}$. The lower Young's modulus results in higher energy production due to the lower fracture aperture induced in the system. Lower initial temperature gradient also increases the amount of the energy produced, specifically when the spacing increases. This is due to the higher initial temperature at the top fracture. However, a local maximum in the net energy production exists for all cases. The optimum spacing for case (i) is between $150 \mathrm{~m}$ and $300 \mathrm{~m}$; for case (ii) is $300 \mathrm{~m}$; and for case (iii) is $150 \mathrm{~m}$. The optimum increases with reducing initial thermal gradient, and reduces with reducing Young's modulus. However, these values are much larger than the values reported by Wu et al. (2016) for rigid matrix.

The coefficient of performance (COP) express the efficiency of the system by comparing the heat output with the power consumed as

$$
\mathrm{COP}=\frac{E_{g}}{E_{p}}
$$

In Figure $15 \mathrm{~b}$ the evolution of COP is plotted for spacing of 50, 150 and $300 \mathrm{~m}$ for case (i): $\mathrm{E}$ $=50 \mathrm{GPa}$ and thermal gradient of $47^{\circ} \mathrm{C} / \mathrm{km}$. The lower spacing shows higher initial COP, but as time elapses the production temperature reduces faster and the production energy reduces. Although that the increase in the aperture improves the injectivity of the system and reduces the pumping energy, however, the overall COP shows a sharp reduction for lower spacing. 
657

658

659

660

661

662

663

664

665

666

667

668

669

670

671

672

673

674

675

676

677

678

\section{Conclusions}

In this study, a coupled THM model is developed to investigate the effect of mechanical interactions between multiple parallel fractures on heat recovery from multiple-fracture EGS. Simulations for various cases are carried out for a system with two and three fractures, where key parameters such as spacing between fractures, Young's modulus of the rock matrix, and the initial temperature gradient are varied and their effects on the production temperature of the system is studied. Results show that

- the mechanical interactions between fractures enhance the flow locally and reduces the efficiency of the system

- The mechanical interactions are affecting the outcome of the system as soon as the spacing between two fractures decreases to less than the fracture radius

- The fracture spacing calculated based on the assumption of rigid matrix, i.e. constant fracture aperture, is not realistic and those spacing should be increased to maximise the net energy recovery

- The optimum spacing for the two-fracture case with the geometry given in this study, varies between $150 \mathrm{~m}$ to $300 \mathrm{~m}$ which is much larger than the proposed values for rigid fractures.

\section{Acknowledgments}

The authors would like to thank the European Union for funding this work through European Union's Horizon 2020 research and innovation programme under grant agreement No 654662 . 
679

680

681

682

683

684

685

686

687

688

689

690

691

692

693

694

695

696

697

698

699

700

701

702

703

704

705

706

\section{References}

Abu Aisha M., Loret B., Eaton D., 2016. Enhanced Geothermal Systems (EGS): Hydraulic fracturing in a thermo-poroelastic framework. J. Petrol. Sci. Eng. 146: 1179-1191.

Baisch, S., Vörös, R., Weidler, R., Wyborn, D., 2009. Investigation of fault mechanisms during geothermal reservoir stimulation experiments in the Cooper Basin, Australia. Bull. Seismol. Soc. Am. 99 (1), 148-158.

Bandis, S.C., Lumsden, A.C., Barton, N.R., 1983. Fundamentals of rock joint deformation. Int. J. Rock Mech. Min. Sci. 20 (6), 249-268.

Barton, N., Bandis, S., Bakhtar, K., 1986. Strength, deformation and conductivity coupling of rock joints. Int. J. Rock Mech. Min. Sci. 22 (3), 121-140.

Bataille A, Genthon P, Rabinowicz M, Fritz B. Modeling the coupling between free and forced convection in a vertical permeable slot: implications for the heat production of an Enhanced Geothermal System. Geothermics 2006; 35: 654-82.

Bodvarsson, G., 1969. On the temperature of water flowing through fractures, J. Geophys. Res. 74(8), 1987-1992.

Bonté, D., Van Wees, J. D., Verweij, J. M., 2012. Subsurface temperature of the onshore Netherlands: new temperature dataset and modelling. Netherlands Journal of Geosciences, 91(4), 491-515.

Chopra, P., Wyborn, D., 2003. Australia's first hot dry rock geothermal energy extraction project is up and running in granite beneath the Cooper Basin, NE South Australia. Proceedings of the Ishihara Symposium: Granites and Associated Metallogenesis, 43.

Dempsey, D., Kelkar, S., Pawar, R., Keating, E., Coblentz, D., 2014. Modeling caprock bending stresses and their potential for induced seismicity during $\mathrm{CO} 2$ injection. Int. J. Greenh. Gas Control 22, 223-236.

GEA., 2016. Annual U.S. Global Geothermal Power Production Report. Geothermal Energy Association (GEA).

Ghassemi, A., Nygren, A., Cheng, A., 2008, Effects of heat extraction on fracture aperture: A poro-thermoelastic analysis, Geothermics 37, 525-539. 
707

708

709

710

711

712

713

714

715

716

Ghassemi A, Tarasovs A, Cheng AH-D. 2003. An Integral equation method for modelling three-dimensional heat extraction from a fracture in hot dry rock. Int. J. Numer. Anal. Meth. Geomech. 27: 989-1004.

Ghassemi A., Zhou X. 2011. A three-dimensional thermo-poroelastic model for fracture response to injection/extraction in enhanced geothermal systems, Geothermics 40, 39-49.

Gringarten, A.C., Witherspoon, P.A. and Ohnishi, Y., 1975. Theory of heat extraction from fractured hot dry rock. Journal of Geophysical Research, 80(8), pp.1120-1124.

Guo B., Fu P., Hao Y., Peters C.A., Carrigan C.R. 2016. Thermal drawdown-induced flow channeling in a single fracture in EGS, Geothermics 61: 46-62.

Jaeger J.C., Cook N.G.W., Zimmerman R.W. 2007, Fundamentals of Rock Mechanics (4th edition), Blackwell Publishing, Oxford, UK.

Khalili, N., Selvadurai, A.P.S., 2003. A fully coupled constitutive model for thermo-hydromechanical analysis in elastic media with double porosity, Geophys. Res. Lett., 30(24), 2268, doi:10.1029/2003GL018838.

Kumar, D. and Ghassemi, A., 2016. A three-dimensional analysis of simultaneous and sequential fracturing of horizontal wells. Journal of Petroleum Science and Engineering, 146, pp.1006-1025.

Llanos, E.M., Zarrouk, S.J., Hogarth, R.A., 2015. Numerical model of the Habanero geothermal reservoir, Australia. Geothermics 53, 308-319.

Martinez,, M., Newell, P., Bishop,, J., Turner, , D., 2013. Coupled multiphase flow and geomechanics model for analysis of joint reactivation during $\mathrm{CO} 2$ sequestration operations. Int. J. Greenh. Gas Control 17, 148-160.

Matthäi S.K., Geiger, S., Roberts, S.G., 2001. The complex systems platform csp3.0: Users guide. Technical report, ETH Zürich Research Reports.

Matthäi, S. K., Nick, H. M., Pain, C., Neuweiler, I., 2010. Simulation of solute transport through fractured rock: a higher-order accurate finite-element finite-volume method permitting large time steps. Transport in porous media, 83(2), 289-318. 
734

735

736

737

738

739

740

741

742

McClure M.W., Horne R.N., 2014. An investigation of stimulation mechanisms in Enhanced Geothermal Systems, Int. J. Rock Mech. Min. Sci. 72: 242-260.

McDermott C.I., Randriamanjatosoa, A.R.L., Tenzer H., Kolditz, O., 2006. Simulation of heat extraction from crystalline rocks: The influence of coupled processes on differential reservoir cooling, Geothermics 35, 321-344.

MIT Report: The future of geothermal energy: impact of enhanced geothermal systems (EGS) on the United States in the $21^{\text {st }}$ century. Massachusetts Institute of Technology, 2006.

Nick, H. M., Paluszny, A., Blunt, M. J., Matthai, S. K. 2011. Role of geomechanically grown fractures on dispersive transport in heterogeneous geological formations. Physical Review E, 84(5), 056301.

Nick, H. M., Matthäi, S. K., 2011. Comparison of three FE-FV numerical schemes for singleand two-phase flow simulation of fractured porous media. Transport in porous media, 90(2), 421-444.

Nejati, M., Paluszny, A., Zimmerman, R.W., 2016. A finite element framework for modelling internal frictional contact in three-dimensional fractured media using unstructured tetrahedral meshes, Comput. Methods Appl. Mech. Engrg. 306, 123-150.

Pandey, S.N., Chaudhuri, A., Kelkar, S., Sandeep, V.R. and Rajaram, H., 2014. Investigation of permeability alteration of fractured limestone reservoir due to geothermal heat extraction using three-dimensional thermo-hydro-chemical (THC) model. Geothermics, 51, pp.46-62.

Pandey, S.N., Chaudhuri, A. and Kelkar, S., 2017. A coupled thermo-hydro-mechanical modeling of fracture aperture alteration and reservoir deformation during heat extraction from a geothermal reservoir. Geothermics, 65, pp.17-31.

Paluszny, A., Zimmerman R.W. 2011. Numerical simulation of multiple 3D fracture propagation using arbitrary meshes. Comput. Methods Appl. Mech. Engrg. 200: 953966. 
761

762

763

764

765

766

767

768

769

770

771

772

773

774

775

776

777

778

779

780

781

782

783

784

785

786

787

788

Rutqvist, J., Barr, D., Datta, R., Gens, A., Millard, A., Olivella, S., Tsang, C.F., Tsang, Y., 2005. Coupled thermal-hydrological-mechanical analyses of the Yucca Mountain Drift Scale Test-Comparison of field measurements to predictions of four different numerical models. Int. J. Rock Mech. Min. Sci. 42 (5-6), 680-697.

Saeid, S., Al-Khoury, R., Nick, H M., Hicks, M. A., 2015. A prototype design model for deep low-enthalpy hydrothermal systems. Renewable Energy, 77, 408-422.

Salimzadeh S., Khalili, N., 2015. A three-phase XFEM model for hydraulic fracturing with cohesive crack propagation, Comput. Geotech. 69, 82-92.

Salimzadeh S., Khalili, N., 2016. A fully coupled XFEM model for flow and deformation in fractured porous media with explicit fracture flow, Int. J. Geomech. 16, 04015091.

Salimzadeh S., Paluszny A., Zimmerman R.W., 2016. Thermal Effects during Hydraulic Fracturing in Low-Permeability Brittle Rocks, In Proceedings of the 50th US Rock Mechanics Symposium, Houston, Texas, 26-29 June 2016, paper ARMA 16-368.

Salimzadeh S., Paluszny A., Zimmerman R.W., 2017a. Finite Element Simulations of Interactions between Multiple Hydraulic Fractures in a Poroelastic Rock, Int. J. Rock Mech. Min. Sci. 99, 9-20.

Salimzadeh S., Paluszny A., Zimmerman R.W., 2017b. Three-dimensional poroelastic effects during hydraulic fracturing in permeable rocks, Int. J. Solids Struct. 108, 153163.

Salimzadeh S., Paluszny A., Nick H.M., Zimmerman R.W., 2018a. A three-dimensional coupled thermo-hydro-mechanical model for deformable fractured geothermal systems, Geothermics, 71, 212-224.

Salimzadeh S., Nick H.M., Zimmerman R.W., 2018b. Thermoporoelastic effects during heat extraction from low permeability reservoirs, Energy, 142, 546-558.

Schweitzer R, Bilgesu HI. 2009. The role of economics on well and fracture design completions of marcellus shale wells. In: Proceedings of the SPE Eastern Regional Meeting (SPE '09), September. p. 423-8.

Stüben, K. 2001. A review of algebraic multigrid. J. Comput. Appl. Math. 128: 281-309. 
789

790

791

792

793

794

795

796

797

798

799

800

801

802

803

804

805

806

807

808

Tsang, C., Barnichon, J., Birkholzer, J., Li, X., Liu, H., Sillen, X., 2012. Coupled thermohydro-mechanical processes in the near field of a high-level radioactive waste repository in clay formations. Int. J. Rock Mech. Min. Sci. 49, 31-44.

Usui T, Salimzadeh S, Paluszny A, Zimmerman RW. Effect of poroelasticity on hydraulic fracture interactions. In: Proceedings of the 6th Biot Conference on Poromechanics, Paris, France, 9-13 July 2017.

Willems, C. J., Nick, H.M., Weltje, G. J., Bruhn, D. F., 2017. An evaluation of interferences in heat production from low enthalpy geothermal doublets systems. Energy, 135, 500512.

Wu, B., Zhang, X., Jeffrey, R. G., Bunger, A. P., Jia, S., 2016. A simplified model for heat extraction by circulating fluid through a closed-loop multiple-fracture enhanced geothermal system. Applied Energy, 183, 1664-1681.

Xie, L., Min, K.B. and Song, Y., 2015. Observations of hydraulic stimulations in seven enhanced geothermal system projects. Renewable Energy, 79, pp.56-65.

Zimmerman, R.W., 1989. Thermal conductivity of fluid-saturated rocks. J. Petrol. Sci. Eng. $3,219-227$.

Zimmerman, R.W., 2000. Coupling in poroelasticity and thermoelasticity. Int. J. Rock Mech. Min. Sci. 37: 79-87.

Zimmerman, R.W., Bodvarsson, G.S. 1996. Hydraulic conductivity of rock fractures. Transp. Porous Media 23: 1-30. 


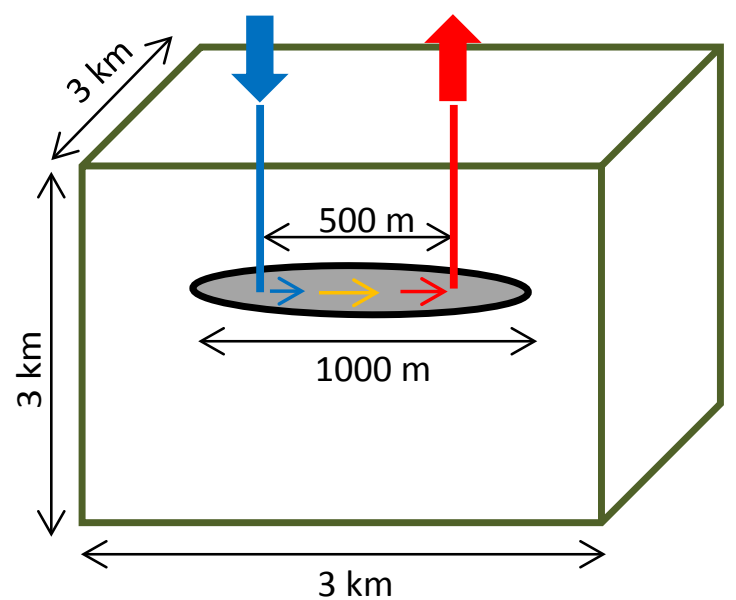

Figure 1. The geometry of the model used for the EGS simulations. 
(a)
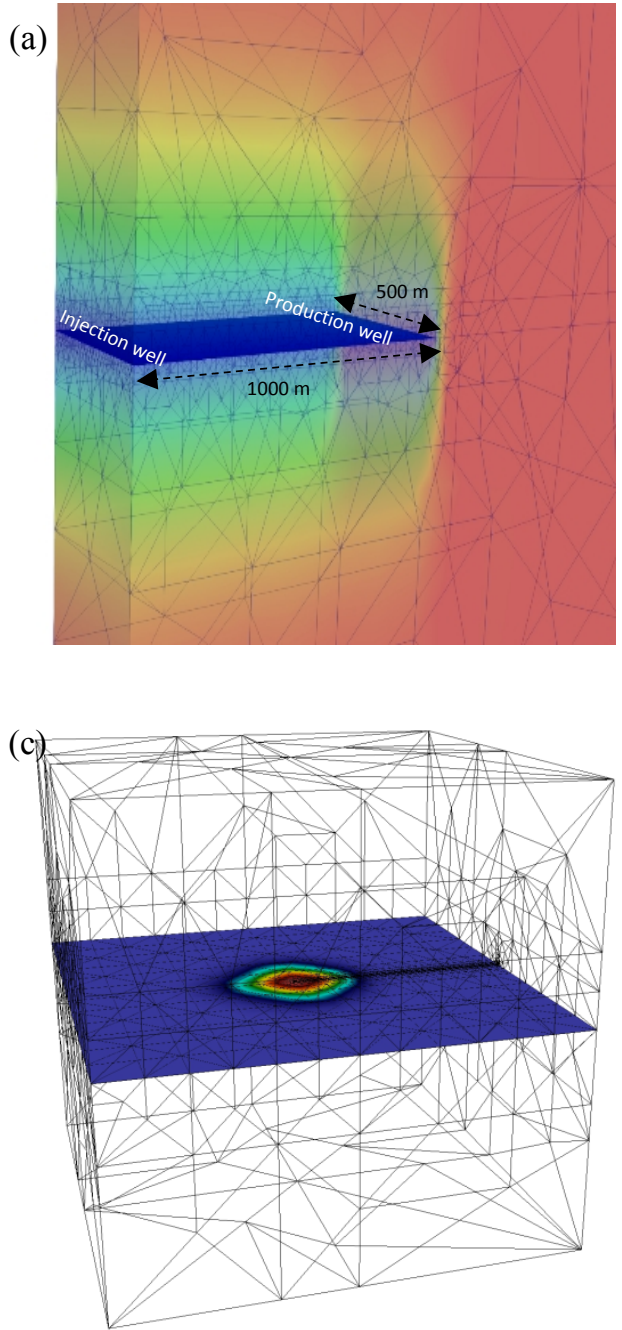

(b)

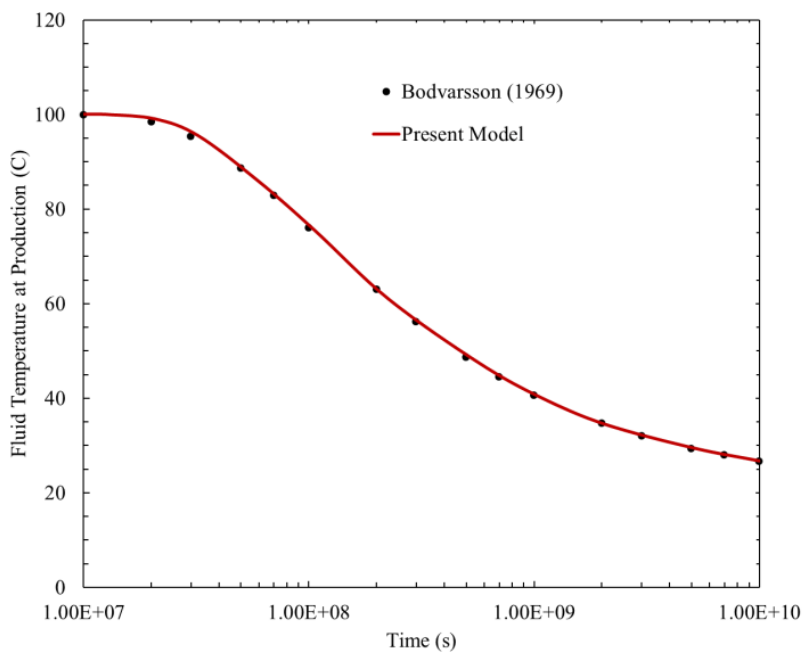

(d)

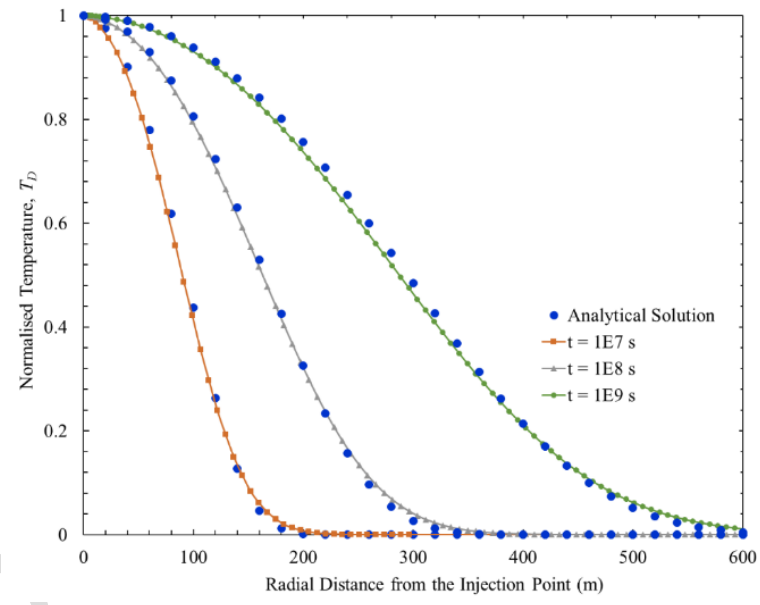

Figure 2. Validation of the present model against the analytical solutions: ( $a$ and b) A one-dimensional flow through a single fracture between injection and production wells proposed by Bodvarsson (1969). (c and d) Radial flow through an infinite fracture proposed by Ghassemi et al. (2003). Normalised temperature is defined as $T_{D}=\left(T_{0}-T\right) /\left(T_{0}-T_{i n j}\right)$ 
(a)

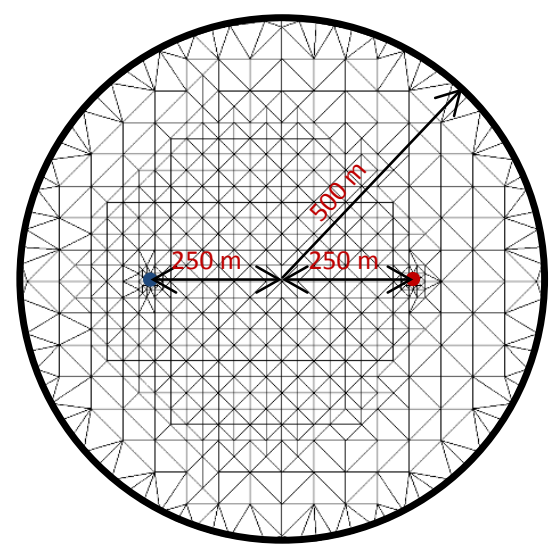

(b)
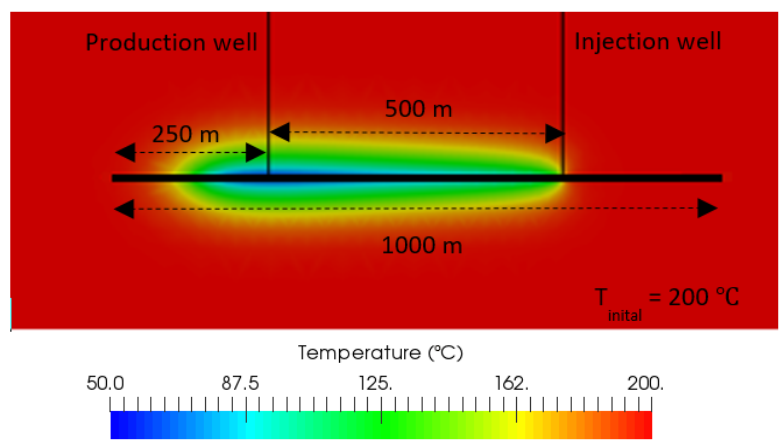

(c)

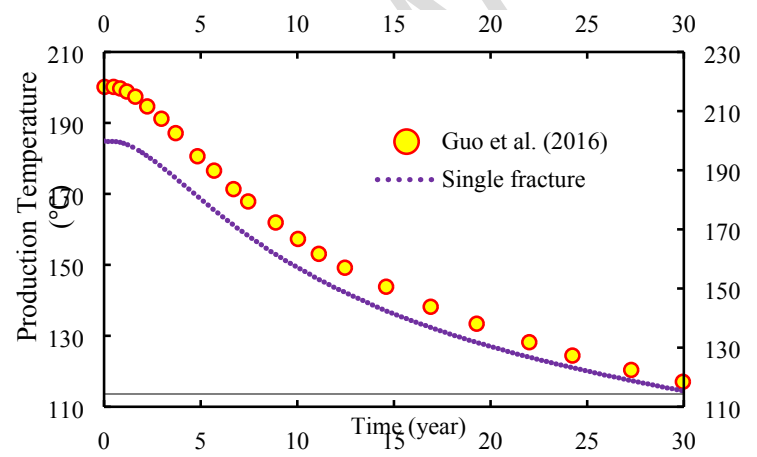

Figure 3. a) The mesh used for the fracture. b) Vertical cross section showing fracture with its dimensions and connected wells. Temperature field is shown at 30 years. c) Comparison between the results of the studied model and results from Guo et al. (2016). 

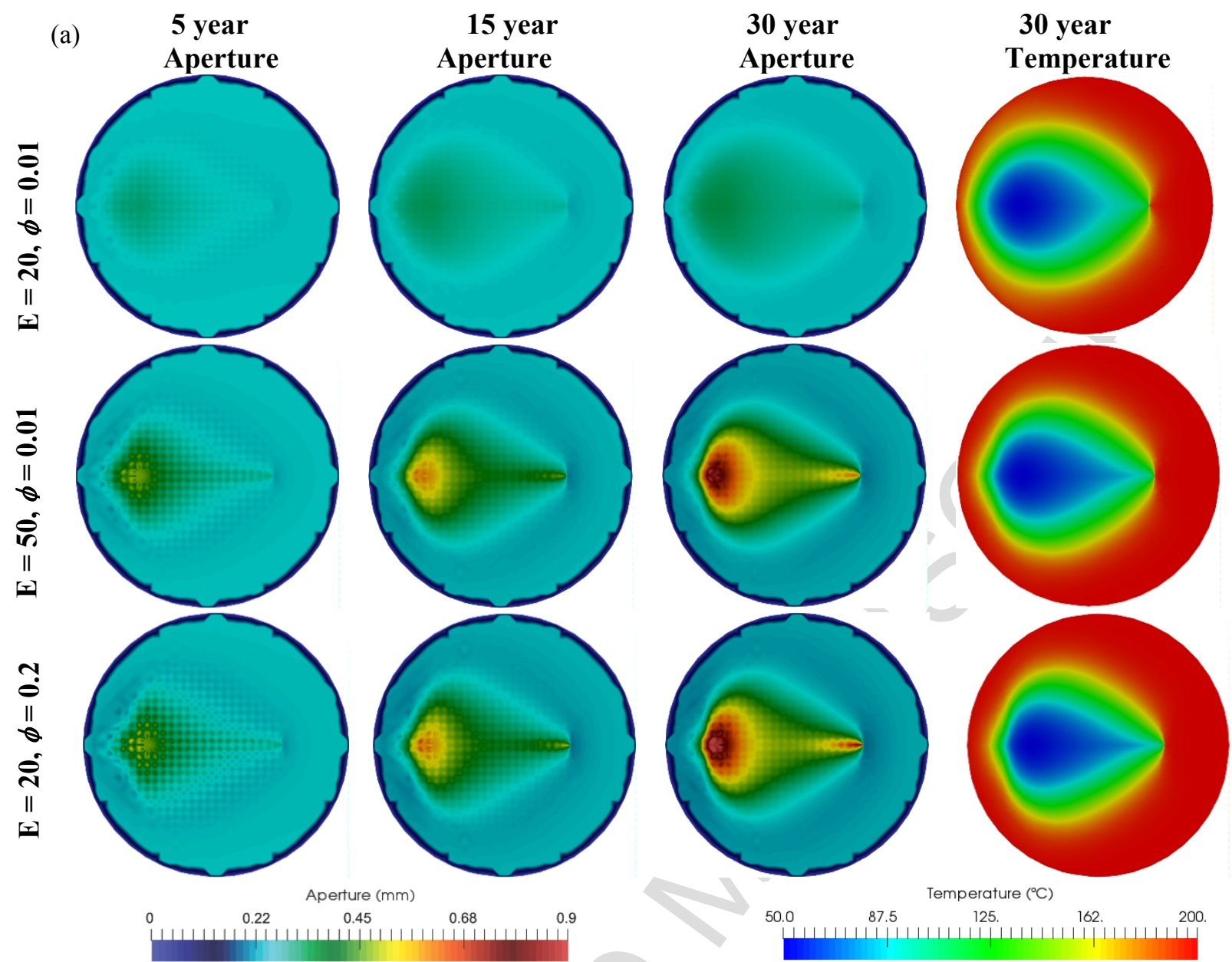

(b)
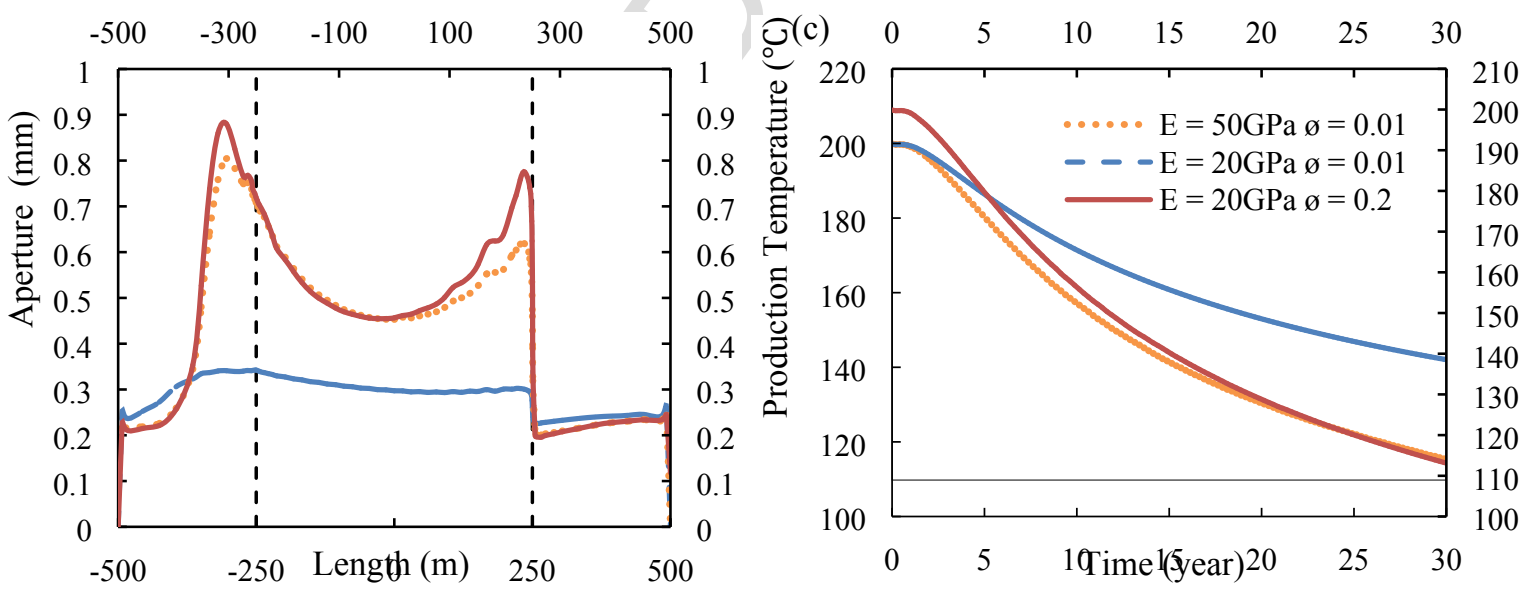

Figure 4. The effect of varying Young's modulus and the matrix porosity on the fracture responses: (a) The aperture and temperature distributions over the fracture for the three cases.

(b) Aperture profile along the line passing through the injection and production points after 30 years. (c) The temperature breakthrough curves for the three cases. 
(a)
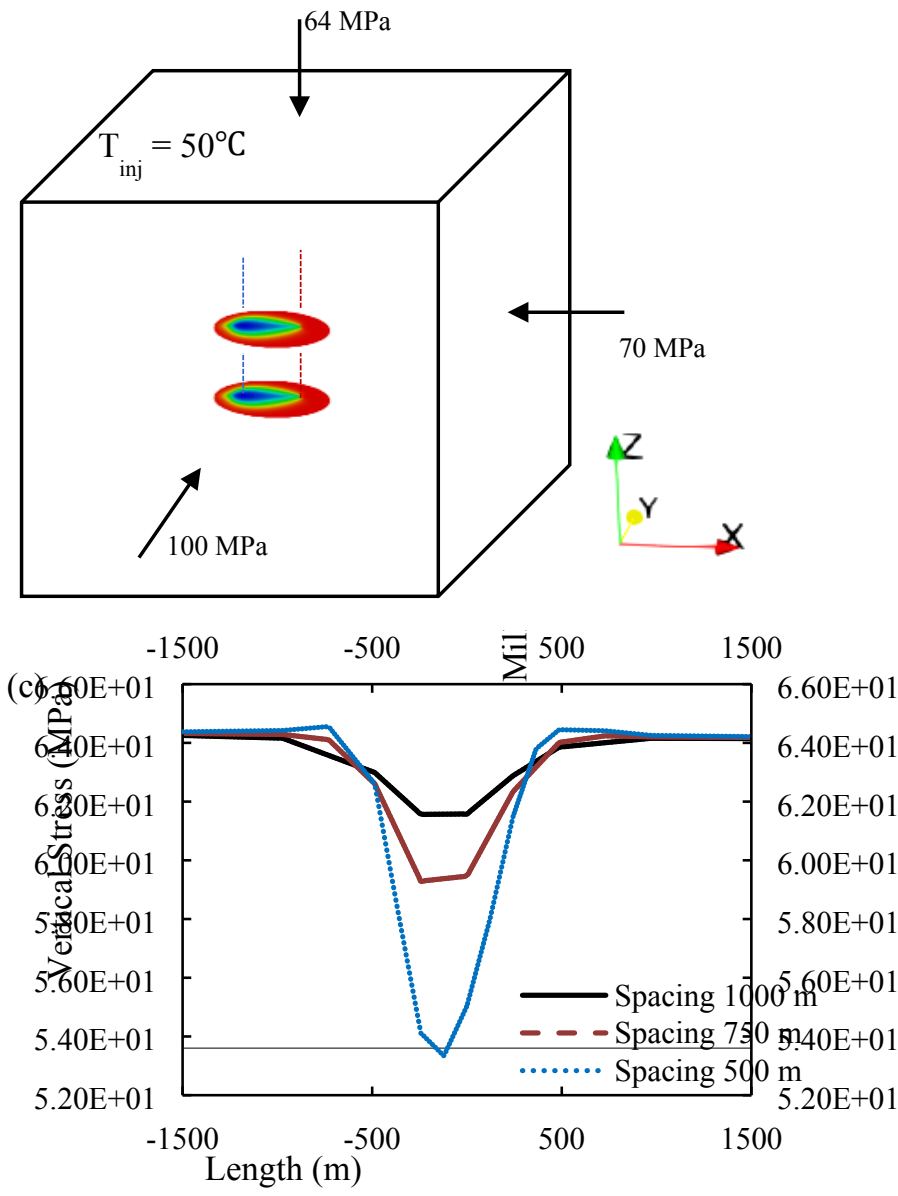

(b)

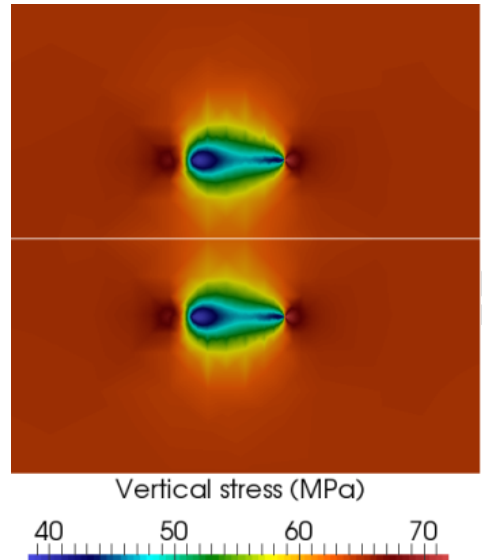

(d)
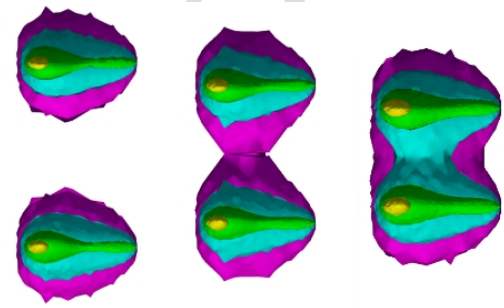

$1000 \mathrm{~m} \quad 750 \mathrm{~m} \quad 500 \mathrm{~m}$

$41 \mathrm{MPa}$ $47.5 \mathrm{MPa}$ $55 \mathrm{MPa}$ $59.3 \mathrm{MPa}$

Figure 5. (a) The geometry used for multiple-fracture EGS simulations. The two fractures are symmetrically situated within the domain. (b) Vertical stress distribution over a centralized vertical cross section for a system with fracture spacing of $1000 \mathrm{~m}$. (c) The vertical stress along the white line shown in (b) is plotted. (d) 3D contour of the vertical stresses around the two fractures, on a vertical plane passing through the injection and production points, for fracture spacing of 1000, 750 and $500 \mathrm{~m}$. 
(a)

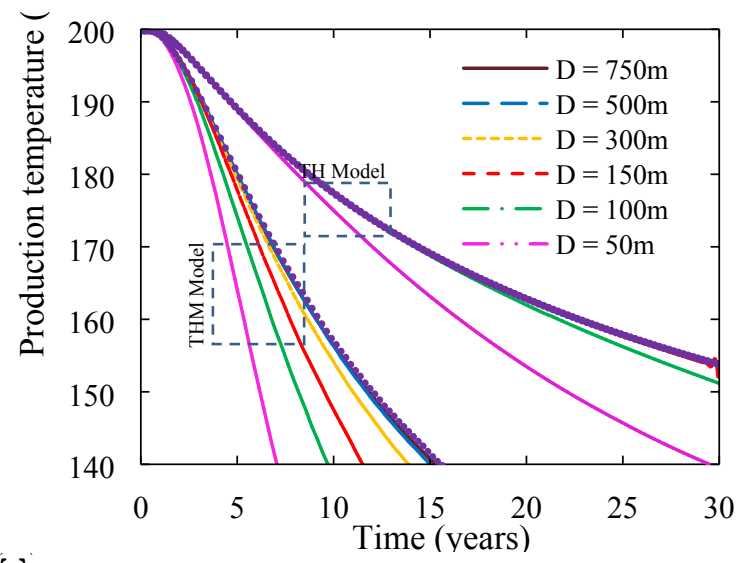

(b)

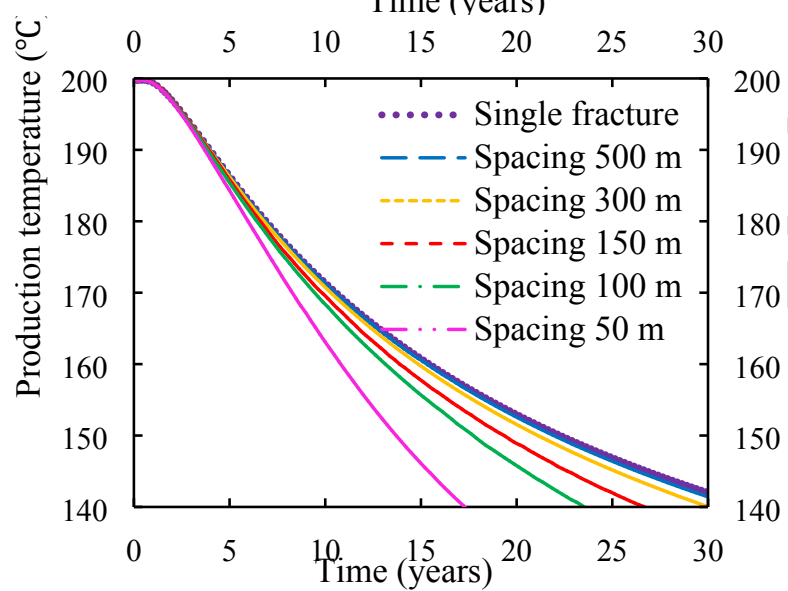

Figure 6. The temperature breakthrough curves for various spacing (D) within an initial uniform temperature of $200^{\circ} \mathrm{C}$ for (a) $\mathrm{E}=50 \mathrm{GPa}$ and (b) $\mathrm{E}=20 \mathrm{GPa}$. The case without mechanical interaction (TH model) is shown in (a) 


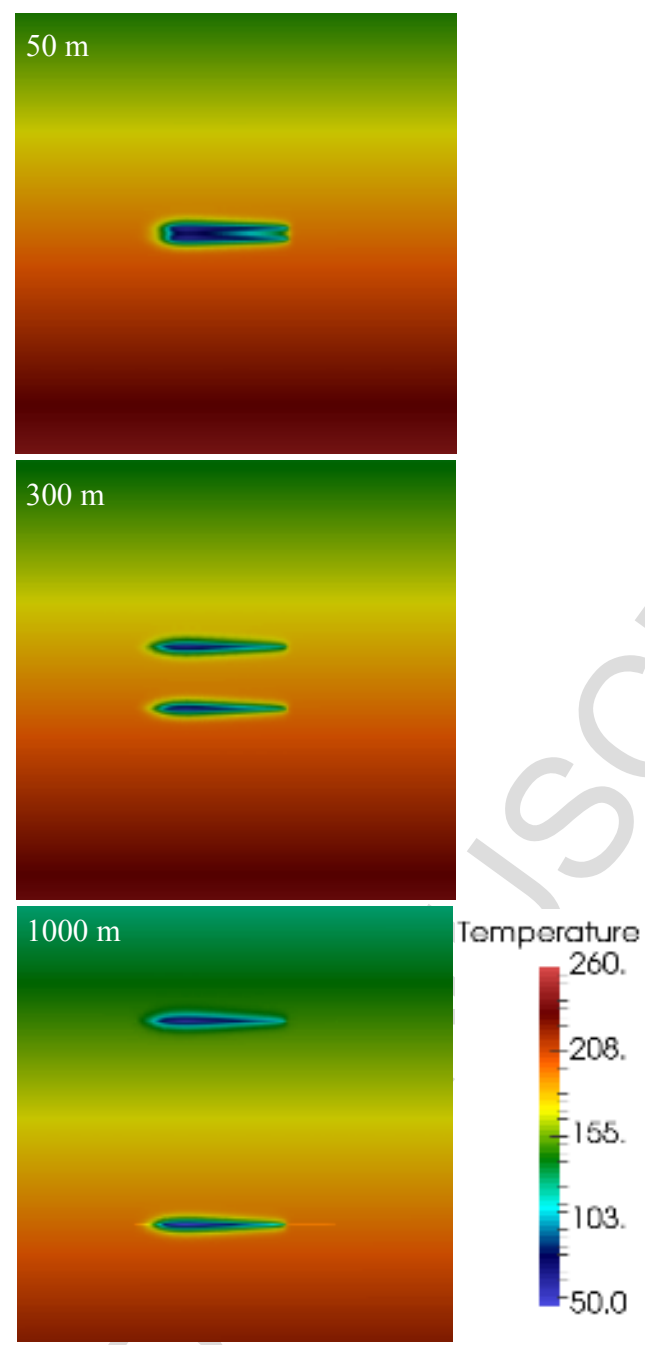

Figure 7. Vertical cross section of the temperature field at 10 years for fracture spacing of $50 \mathrm{~m}, 300 \mathrm{~m}$ and $1000 \mathrm{~m}$ for a temperature gradient at $47^{\circ} \mathrm{C} / \mathrm{km}$. The initial temperature at the bottom fracture is fixed at $200^{\circ} \mathrm{C}$ for all cases 
(a)

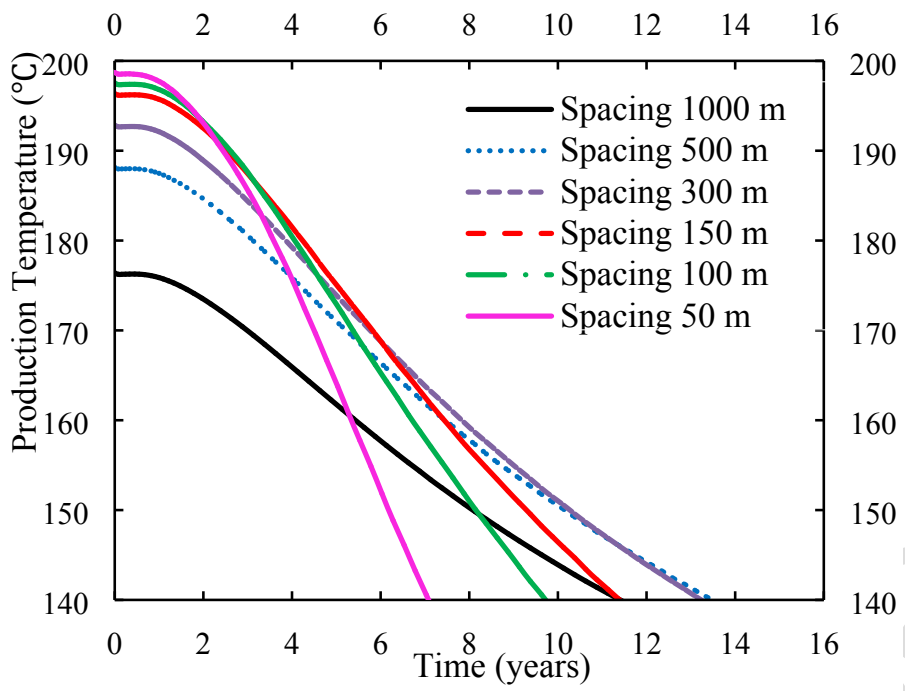

(b)

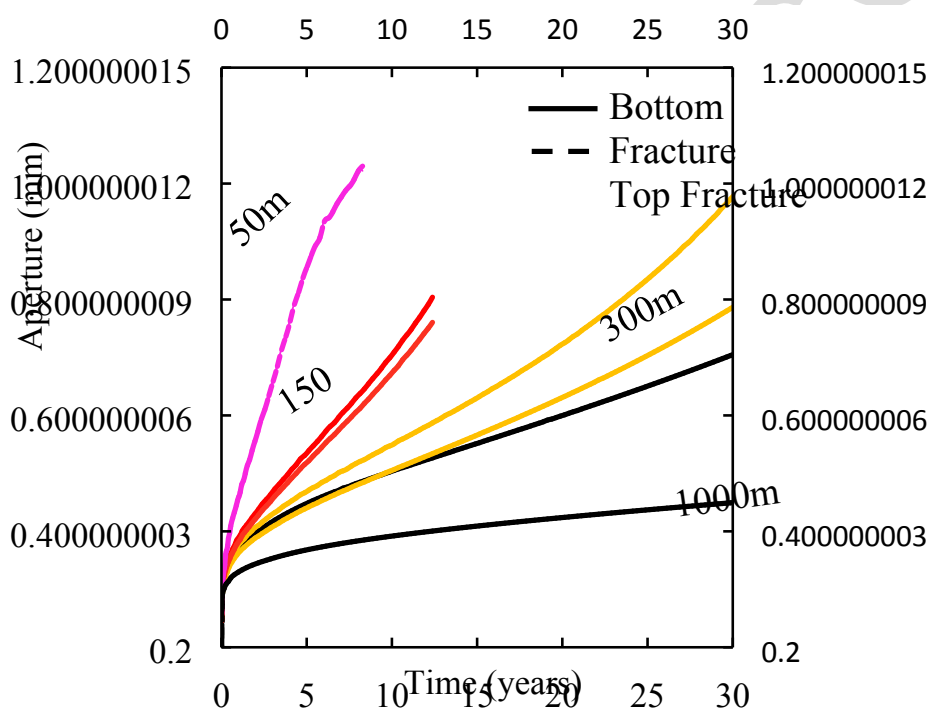

Figure 8. (a) The temperature breakthrough curve where a temperaure gradient of $47^{\circ} \mathrm{C} / \mathrm{km}$ is introduced. (b) Aperture evolution for bottom (solid lines) and top (dashed lines) fracture for different fracture spacing. As the bottom fracture experience a higher temperature variation, the aperture tends to increase more 


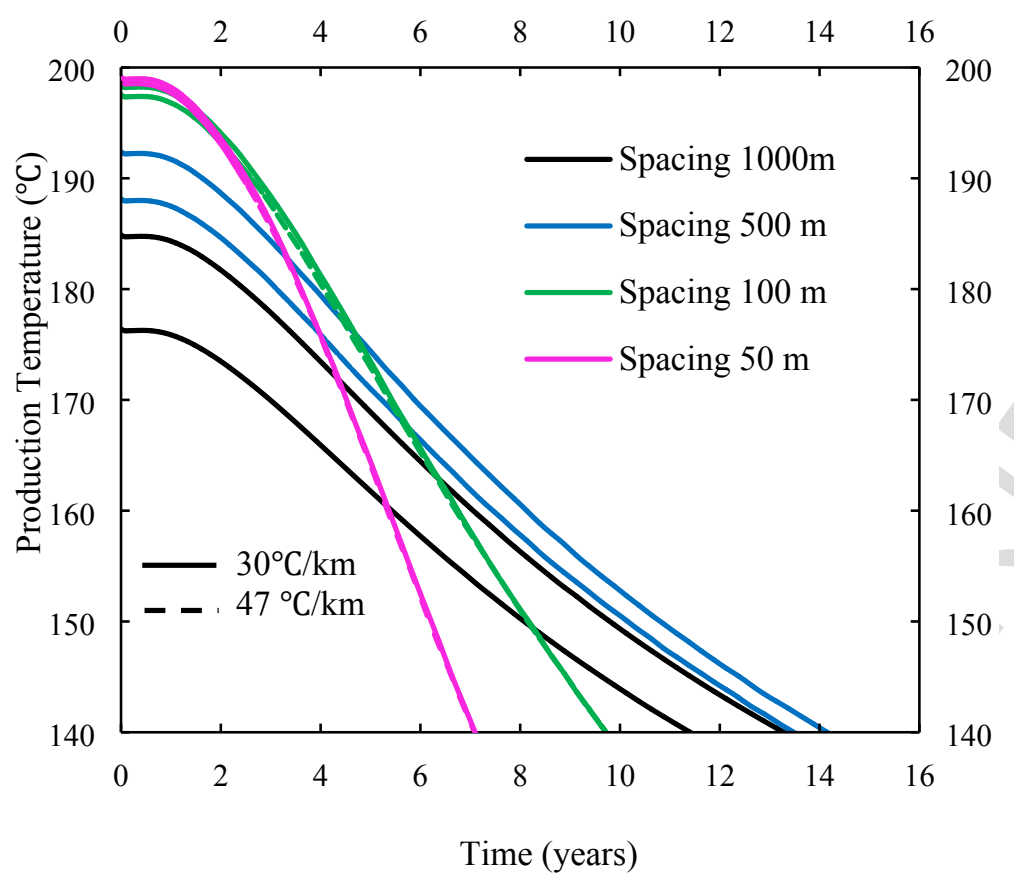

Figure 9. The temperature breakthrough curves for two temperature gradients: $47^{\circ} \mathrm{C} / \mathrm{km}$ (dashed lines) and $30^{\circ} \mathrm{C} / \mathrm{km}$ (solid lines), in the two-fracture EGS with different spacing. 
(a)

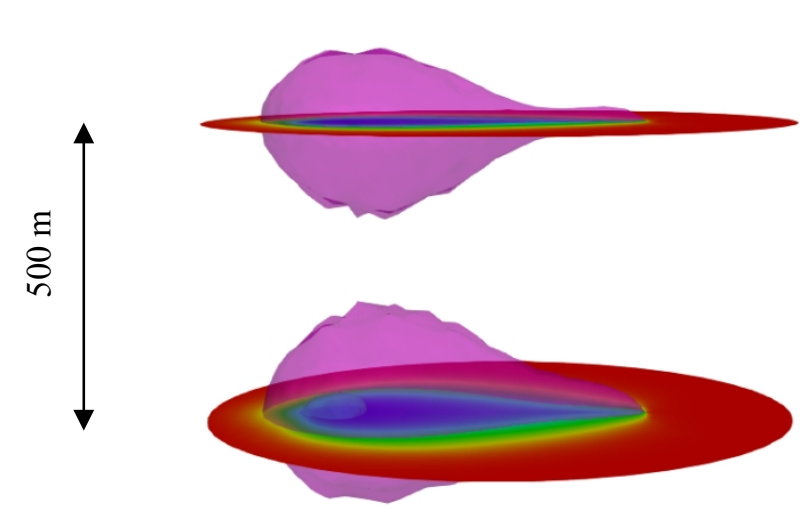

(c)

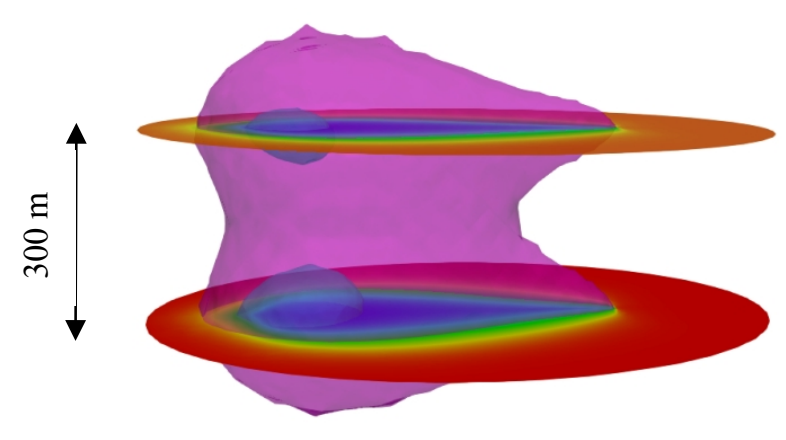

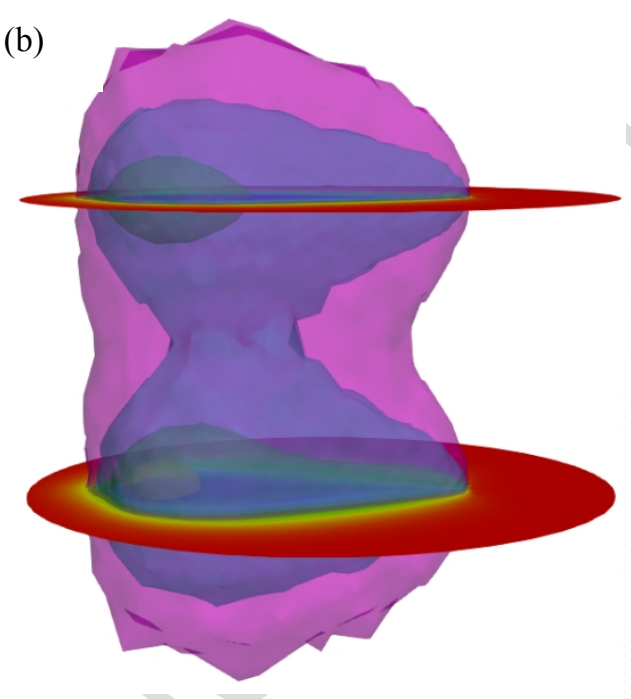

(d)

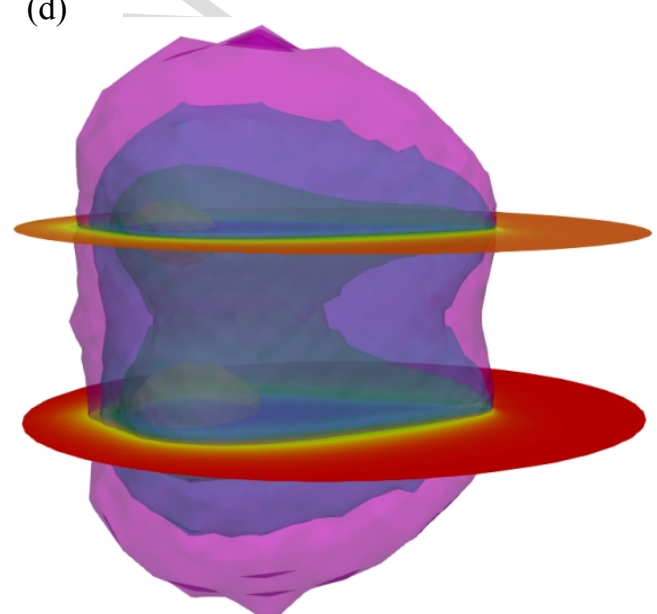

Figure 10. Vertical stress distribution around two parallel fractures. (a) $\mathrm{E}=20 \mathrm{GPa}$, spacing $=$ $500 \mathrm{~m},(\mathrm{~b}) \mathrm{E}=50 \mathrm{GPa}$, spacing $=500 \mathrm{~m}$, (c) $\mathrm{E}=20 \mathrm{GPa}$, spacing $=300 \mathrm{~m},(\mathrm{~d}) \mathrm{E}=50 \mathrm{GPa}$, spacing $=300 \mathrm{~m}$ 

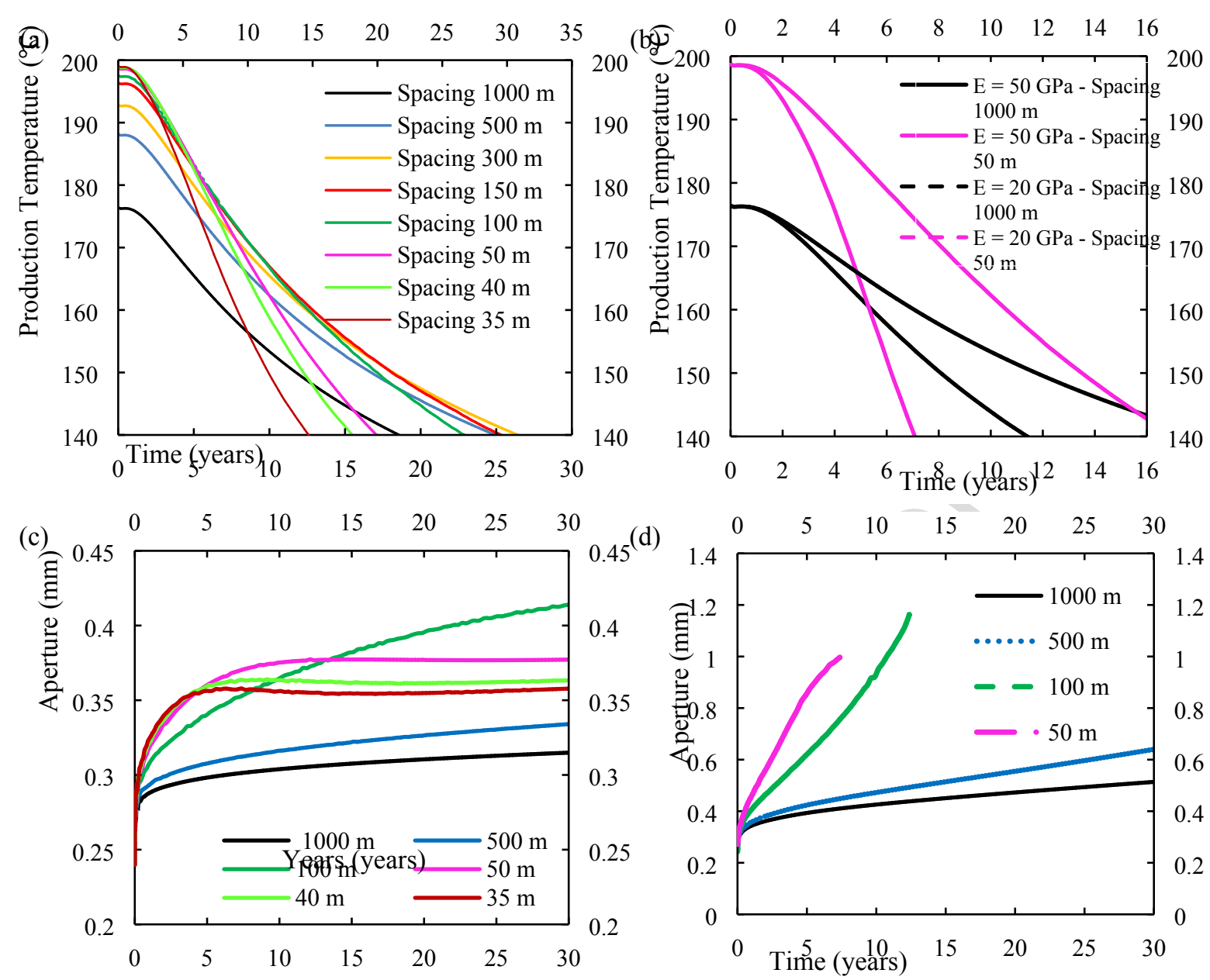

Figure 11. (a) The temperature breakthrough curves for $\mathrm{E}=20 \mathrm{GPa}$ for different spacing. (b) Comparison between the production tempeartre for cases of $50 \mathrm{~m}$ and $1000 \mathrm{~m}$ spacing with $\mathrm{E}$ $=50 \mathrm{GPa}$ (solid lines) and $\mathrm{E}=20 \mathrm{GPa}$ (dashed lines). Aperture evolution at the injection point at the bottom fracture during the lifetime of the EGS for (c) $E=20 \mathrm{GPa}$ and (d) $E=50$ $\mathrm{GPa}$ 


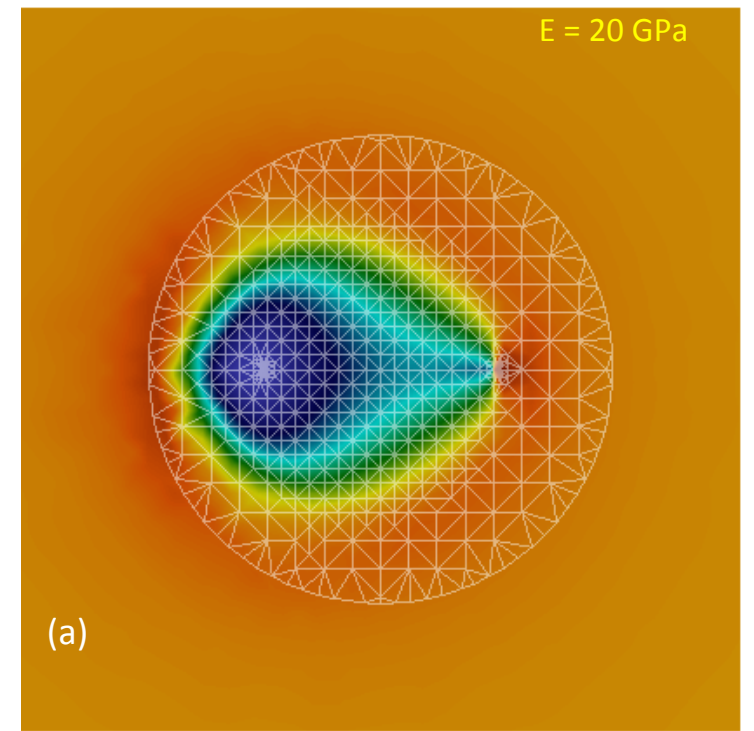

Vertical stress (MPa)

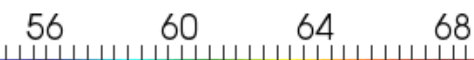

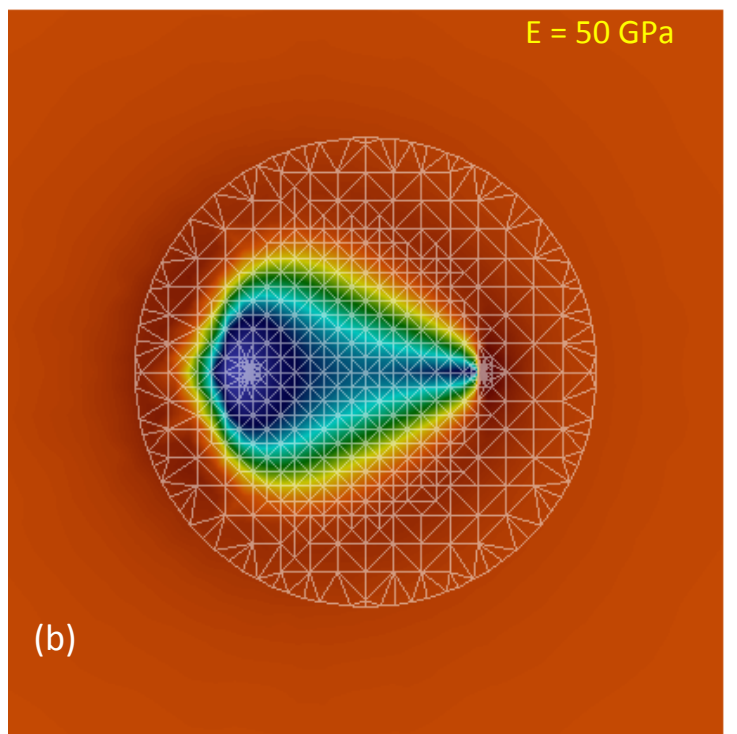

Vertical stress (MPa)

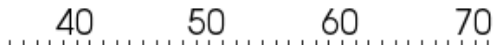

Figure 12. Horizontal cross section through bottom fracture for a system with fracture spacing of $300 \mathrm{~m}$. (a) Young's modulus is $20 \mathrm{GPa}$, (b) Young's modulus is $50 \mathrm{GPa}$ 


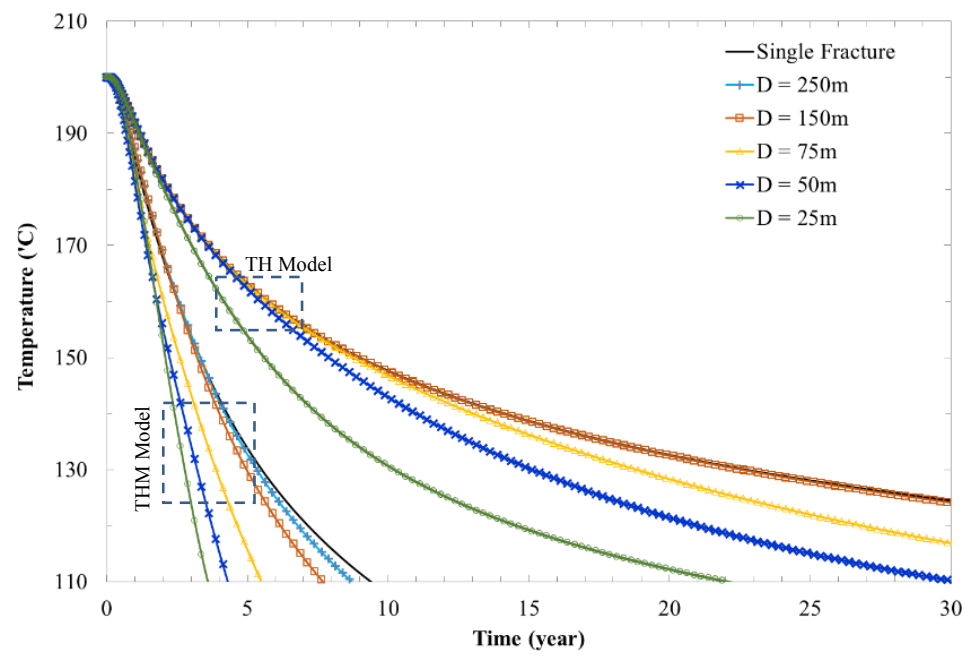

Figure 13. The temperature breakthrough curves for the case with two small fractures $(\mathrm{R}=$ $250 \mathrm{~m})$ with different spacings $(\mathrm{D}=25 \mathrm{~m}$ to $250 \mathrm{~m})$ 
(a)
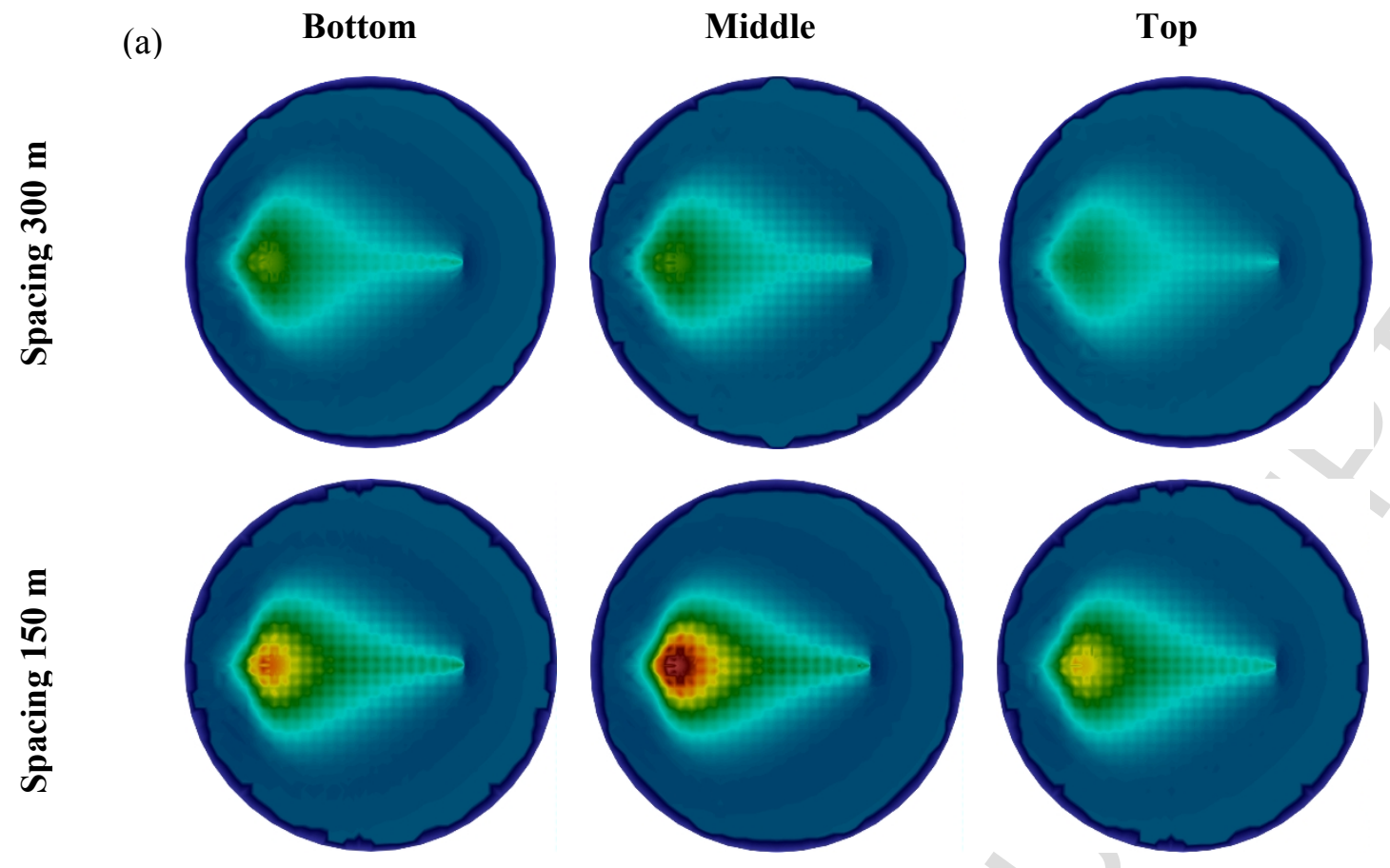

Aperture (mm)
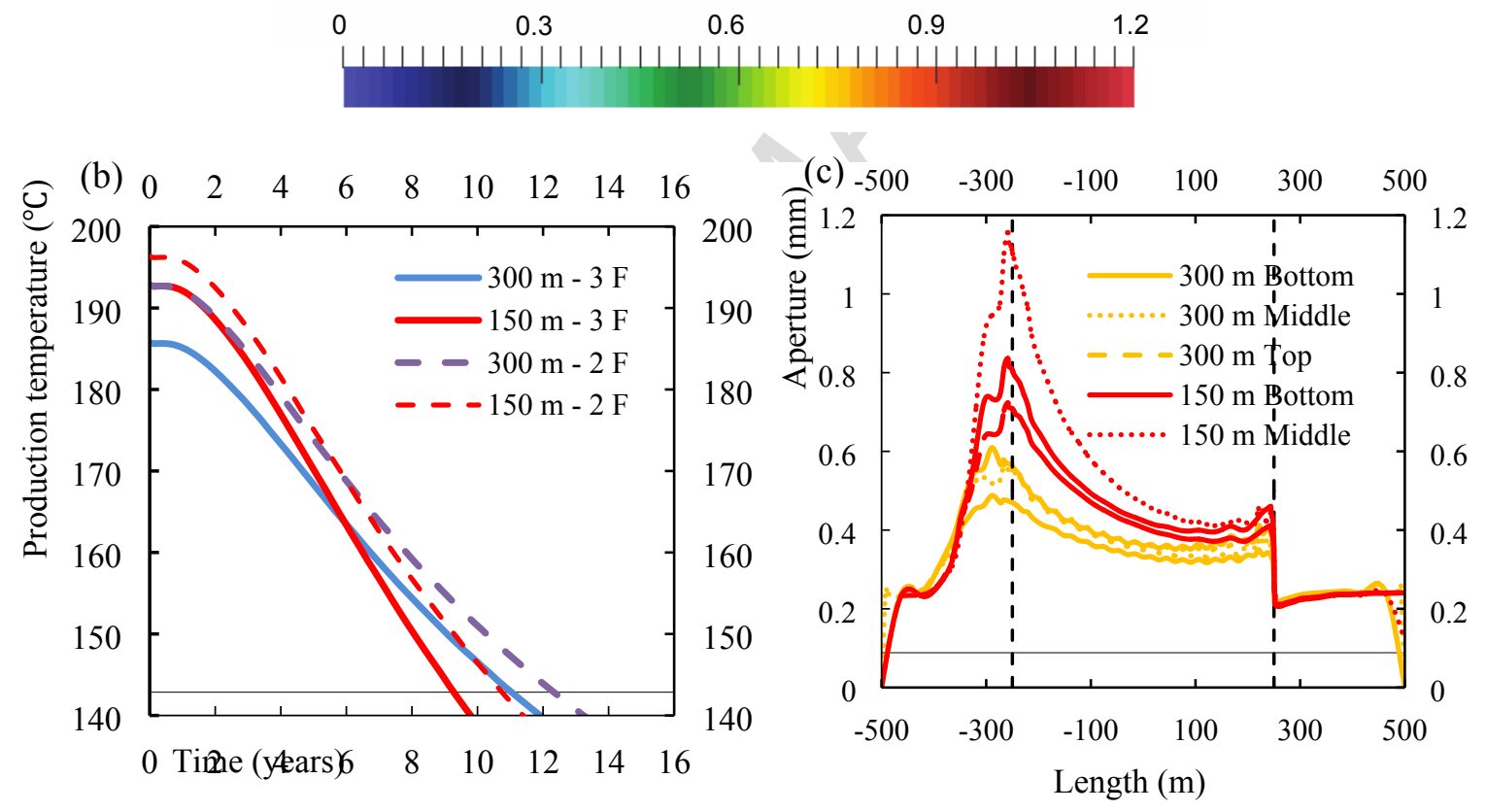

Figure 14. (a) Aperture distribution at 10 years for the bottom, middle and top fractures. (b) Production temperature versus time for two- and three-fracture cases. (c) Aperture profile along the line passing through the injection and production wells at 10 years. 


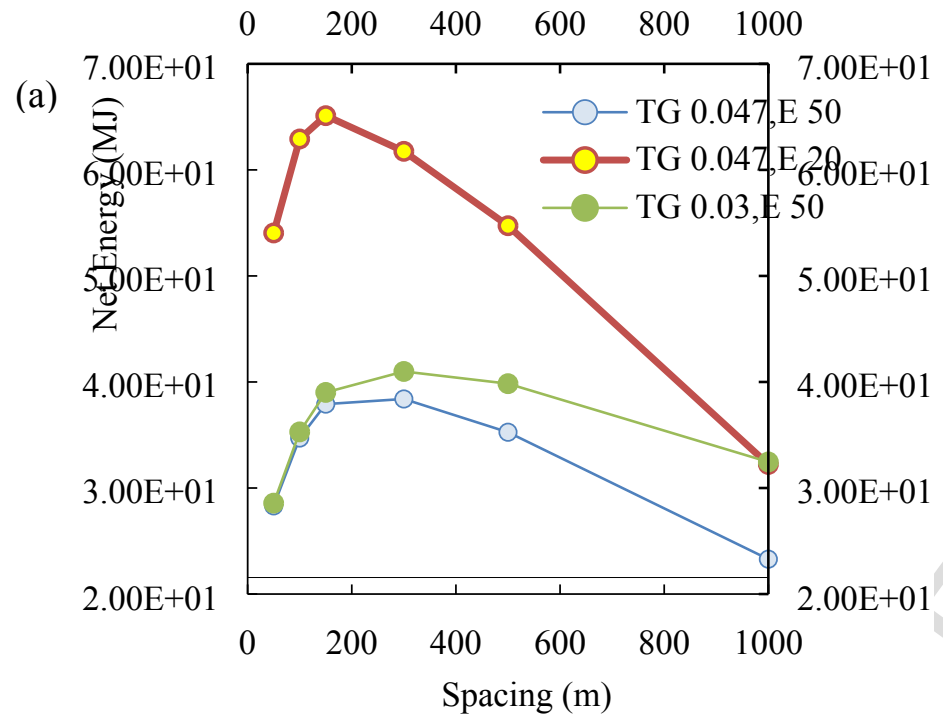

(b)

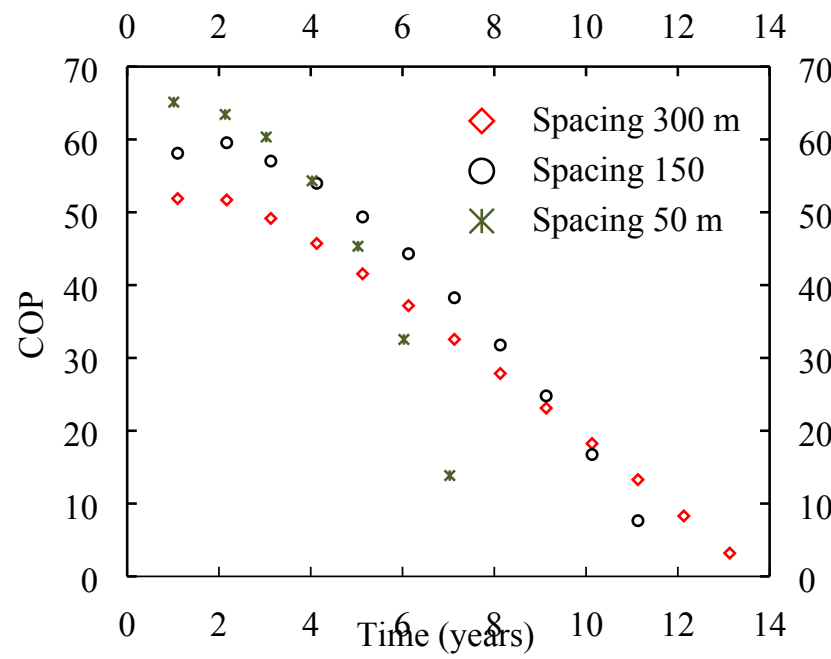

Figure 15. (a) The net energy for all spacing is shown for the three different scenarios for a system with two parallel fractures. (b) The COP for $\mathrm{E}=50 \mathrm{GPa}$ and temperature gradient of $0.047^{\circ} \mathrm{C} / \mathrm{m}$ 
Highlights

- Thermoelastic interactions between multiple fractures are modelled

- Fractures are modelled as discontinuous surfaces within 3D matrix

- Thermoelastic interactions improves the conductivity of the fracture

- The optimum spacing is rather dictated by the thermoelastic deformations

- The optimum fracture spacing are higher for deformable matrix 
Table 1- The rock and fluid properties used in the simulations

\begin{tabular}{lll}
\hline Parameter & Value & Unit \\
\hline Matrix porosity $(\phi)$ & 0.01 & - \\
Matrix permeability $\left(k_{m}\right)$ & $1 \times 10^{-20}$ & $\mathrm{~m}^{2}$ \\
Solid density $\left(\rho_{s}\right)$ & 2500 & $\mathrm{~kg} / \mathrm{m}^{3}$ \\
Young's modulus $(E)$ & 50 & $\mathrm{GPa}$ \\
Poisson's ratio $(v)$ & 0.25 & - \\
Specific heat capacity of the solid $\left(C_{s}\right)$ & 790 & $\mathrm{~J} / \mathrm{kg}^{\circ} \mathrm{C}$ \\
Specific heat capacity of the fluid $\left(C_{f}\right)$ & 4460 & $\mathrm{~J} / \mathrm{kg}^{\circ} \mathrm{C}$ \\
Volumetric thermal expansion coefficient of the solid $\left(\beta_{s}\right)$ & $3.03 \times 10^{-5}$ & ${ }^{\circ} \mathrm{C}$ \\
Volumetric thermal expansion coefficient of the fluid $\left(\beta_{f}\right)$ & $7.66 \times 10^{-4}$ & ${ }^{\circ} \mathrm{C}$ \\
Fluid dynamic viscosity $\left(\mu_{f}\right)$ & $1.42 \times 10^{-4}$ & $\mathrm{~Pa} \mathrm{~s}$ \\
Fluid compressibility $\left(c_{f}\right)$ & $5.11 \times 10^{-10}$ & $\mathrm{~Pa}-1$ \\
Thermal conductivity of the solid $\left(\lambda_{s}\right)$ & 3.5 & $\mathrm{~W} / \mathrm{m}^{\circ} \mathrm{C}$ \\
Thermal conductivity of the fluid $\left(\lambda_{f}\right)$ & 0.6 & $\mathrm{~W} / \mathrm{m}^{\circ} \mathrm{C}$ \\
\hline
\end{tabular}

